\title{
Review \\ Evolution and Targeting of Myeloid Suppressor Cells in Cancer: A Translational Perspective
}

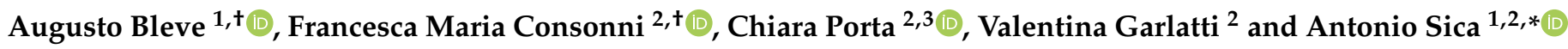 \\ 1 Humanitas Clinical and Research Center-IRCCS, 20089 Rozzano, Italy; augusto.bleve@humanitasresearch.it \\ 2 Department of Pharmaceutical Sciences, Università del Piemonte Orientale "Amedeo Avogadro", \\ 28100 Novara, Italy; francesca.consonni@uniupo.it (F.M.C.); chiara.porta@uniupo.it (C.P.); \\ valentina.garlatti@uniupo.it (V.G.) \\ 3 Center for Translational Research on Autoimmune \& Allergic Diseases (CAAD), \\ Università del Piemonte Orientale "Amedeo Avogadro", 28100 Novara, Italy \\ * Correspondence: antonio.sica@uniupo.it or antonio.sica@humanitasresearch.it; Tel.: +39-(0)-321-375881; \\ Fax: +39-(0)-321-375821 \\ + These authors contributed equally to the work.
}

check for updates

Citation: Bleve, A.; Consonni, F.M.; Porta, C.; Garlatti, V.; Sica, A. Evolution and Targeting of Myeloid Suppressor Cells in Cancer: A Translational Perspective. Cancers 2022, 14, 510. https://doi.org/ 10.3390/cancers 14030510 Academic Editor: Mary Poupot Received: 30 December 2021 Accepted: 19 January 2022 Published: 20 January 2022

Publisher's Note: MDPI stays neutral with regard to jurisdictional claims in published maps and institutional affiliations.

Copyright: () 2022 by the authors. Licensee MDPI, Basel, Switzerland. This article is an open access article distributed under the terms and conditions of the Creative Commons Attribution (CC BY) license (https:// creativecommons.org/licenses/by/ $4.0 /)$.
Simple Summary: Immunotherapy is achieving impressive results in the treatment of several cancers. While the main strategies aim to re-invigorate the specific lymphocyte anti-tumor response, many studies underline that altered myeloid cell frequency and functions can dramatically interfere with the responsiveness to cancer therapies. Therefore, many novel strategies targeting TAMs and MDSCs in combination with classical treatments are under continuous evolution at both pre-clinical and clinical levels, showing encouraging results. Herein, we depict a comprehensive overview of myeloid cell generation and function in a cancer setting, and the most relevant strategies for their targeting that are currently in clinical use or under pre-clinical development.

\begin{abstract}
In recent years, the immune system has emerged as a critical regulator of tumor development, progression and dissemination. Advanced therapeutic approaches targeting immune cells are currently under clinical use and improvement for the treatment of patients affected by advanced malignancies. Among these, anti-PD1/PD-L1 and anti-CTLA4 immune checkpoint inhibitors (ICIs) are the most effective immunotherapeutic drugs at present. In spite of these advances, great variability in responses to therapy exists among patients, probably due to the heterogeneity of both cancer cells and immune responses, which manifest in diverse forms in the tumor microenvironment (TME). The variability of the immune profile within TME and its prognostic significance largely depend on the frequency of the infiltrating myeloid cells, which often represent the predominant population, characterized by high phenotypic heterogeneity. The generation of heterogeneous myeloid populations endowed with tumor-promoting activities is typically promoted by growing tumors, indicating the sequential levels of myeloid reprogramming as possible antitumor targets. This work reviews the current knowledge on the events governing protumoral myelopoiesis, analyzing the mechanisms that drive the expansion of major myeloid subsets, as well as their functional properties, and highlighting recent translational strategies for clinical developments.
\end{abstract}

Keywords: innate immunity; tumor-associated myeloid cells; tumor-associated macrophages (TAMs); myeloid-derived suppressor cells (MDSCs); tumor microenvironment; cancer immunotherapy

\section{Introduction}

While the functional plasticity of myeloid cells has assumed considerable interest as a potential level of therapeutic intervention in tumors, the mechanisms that drive their protumoral phenotype are only partially elucidated, and research is mainly focused on understanding the intratumoral signals capable of polarizing myeloid cell functions. Nevertheless, recent observations highlighted that the final state of activation and heterogeneity 
of immune cell responses in cancer bearers is conferred through a multistep process, which includes lineage commitment and expansion of hematopoietic progenitors in the bone marrow (i.e., hematopoiesis), their subsequent mobilization to the periphery and the final recruitment and conditioning in response to signals that operate in the TME [1].

Several inflammatory insults drive "pathological myelopoiesis" [2], including pathogenassociated molecular patterns (PAMPs) and damage-associated molecular patterns (DAMPs) [3], which are sensed by pattern recognition receptors (PRRs) [4]. Innate immune cells activated through PRRs provide the source for cytokines and myelopoietic growth factors, acting on myeloid progenitors. Of relevance, activation of hematopoietic stem cells (HSCs) to persistent low-grade inflammation in cancer or over-activation (i.e., acute infections or sepsis) perpetuates and increases myelopoiesis at the expense of lymphopoiesis, which favors immunosuppression [5]. To complement these mechanisms, new evidence indicates the existence of metabolic gates which control the suppressor myeloid cells in cancer [6], as well as their epigenetic dysfunctions [7]. The gap in the knowledge still present on the mechanisms that drive myelopoietic alterations during tumor growth, as well as on their contribution to tumor development and resistance to anticancer therapies, is becoming increasingly evident. A better understanding of the processes that integrate myelopoietic response, mobilization of myeloid progenitors, their recruitment and functional diversion into the tumor site could herald new advanced therapeutic approaches, also identifying new markers and criteria for personalized therapy.

In accordance with this, increasing evidence shows dysregulated cellular signaling and metabolism in myeloid cell subsets that infiltrate immunologically cold tumors resistant to immune checkpoint inhibitors (ICIs), chemo- and radio-therapy, characterized by a lack in T and NK cell infiltrates, and the accumulation of myeloid-derived suppressor cells (MDSCs), tumor-associated macrophages (TAMs) and tolerogenic dendritic cells (DCs) [8,9].

\section{Emergency Myelopoiesis}

In stationary conditions, hematopoiesis is characterized by strictly controlled and balanced cell transition phases, which allow the conservation of both resident and circulating lymphoid and myeloid cells. In this hierarchically organized process, the apex of the pyramid is occupied by HSCs [10]. HSCs reside primarily in the bone marrow (BM), within a specialized micro-environment defined as the HSC niche. The latter comprises different cellular constituents, which include cells of mesenchymal origin, endothelial cells and HSC progeny, that cooperate to generate effective defenses against pathogens. HSCs are endowed with the ability to control self-renewal and differentiative cell divisions, producing multipotent and lineage-committed progenitors, that in turn can terminally differentiate into both lymphoid and myeloid progenitors [10,11]. Common myeloid progenitors (CMPs), in particular, undergo further selective differentiation, generating granulocyte-macrophage progenitors (GMPs) and monocyte-dendritic cell progenitors (MDPs) [11].

These highly coordinated events are altered by tumors that provide immunological stresses able to amend the hematopoietic output and consequently shape the TME composition, by the recruitment of both mature and immature myeloid precursors characterized by an immunosuppressive potential $[1,12]$. This pathological expansion of protumoral myeloid cells is defined as "emergency myelopoiesis". These suppressor populations include monocytic and granulocytic myeloid-derived suppressor cells (M-MDSCs and PMN-MDSCs, respectively), as well as tumor-associated macrophages (TAMs) (Figure 1) and neutrophils (TANs) $[1,13]$. In addition, the TME is also characterized by the presence of regulatory T cells (Tregs), T-helper 17 cells (Th17), as well as other myeloid cell subsets (not of main interest for this review), including regulatory dendritic cells (DCregs), Tie-2 monocytes and mast cells, which support cancer growth and spread [14,15]. 


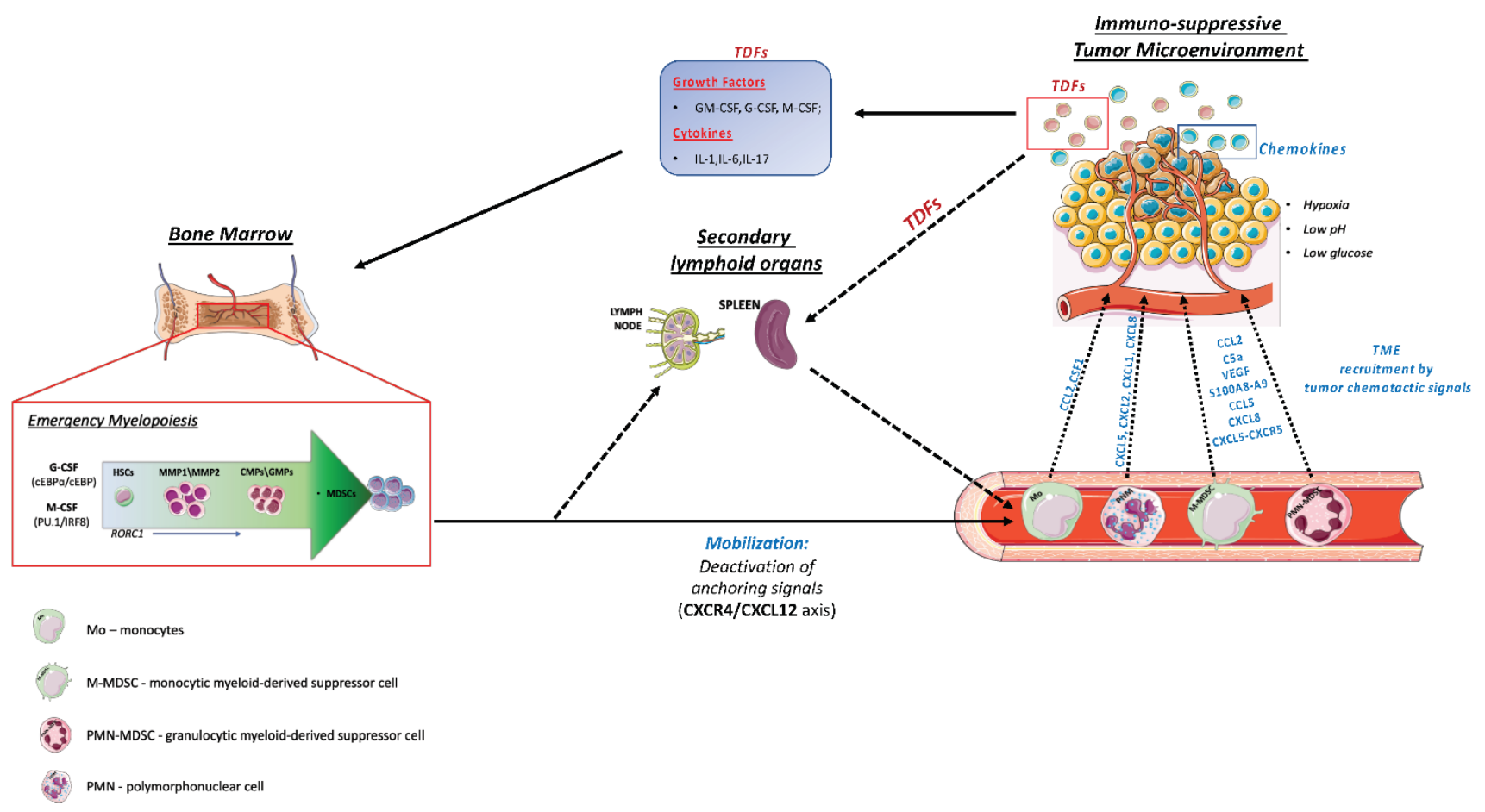

Figure 1. Schematic representation of myelopoiesis in cancer bearers. Tumor-derived factors (TDFs), endowed with myelopoietic activity (i.e., myeloid growth factors/CSFs and cytokines), alter the myelopoietic output, inducing the expansion and mobilization of different subtypes of myeloid suppressor cells. The transcription factor RORC1 is a crucial mediator of this myelopoietic response in emergency conditions. Deactivation of anchoring signals, such as the retention axis CXCR4/CXCL12, induces the mobilization of myeloid cells to the periphery. Once in the circulation, myeloid cells reach the secondary lymphoid organs (i.e., lymph nodes and spleen) and are recruited at the tumor site in response to chemotactic signals. Immunosuppressive cytokines and factors released within the tumor microenvironment (i.e., IL-10, TGF $\beta$, PGE2) and micro physiological conditions (i.e., hypoxia, low glucose levels, low $\mathrm{pH}$ ) concur to complete the pro-tumoral skewing of myeloid cells. This multistep process establishes local and systemic immunosuppression, which represents a major obstacle for anticancer immunotherapy.

Similarly to infections, cancers promote a switch from homeostatic to emergency myelopoiesis, through the sensing of danger signals from tumor tissue operated by pattern recognition receptors (PRRs) and the consequent activation of downstream signaling pathways that lead to overproduction of myelopoietic cytokines, such as granulocyte (GCSF) and macrophage colony-stimulating factors (M-CSF) [16], as well as hematopoietic cytokines [1]. Among these, interleukin (IL)-17A induces both G-CSF- and stem-cell-factormediated neutrophilia [1].

IL-1 and IL-6 represent additional players. In particular, IL-1 has been found to increase the proliferation and differentiation rate of HSCs through the induction of PU.1 and the consequent upregulation of both the M-CSF/CSF1 (Csf1r) and the GM-CSF (Csf2ra) receptors [17]. Of note, while the TNF $\alpha$ is primarily recognized as an immunostimulatory, anti-tumoral cytokine, an opposing effect of its chronic production emerged, inducing an accumulation of immunosuppressive tumor-promoting myeloid cells [18,19]. Interestingly, aberrant myelopoiesis may be reinforced by chemotherapy (CT), through a mechanism defined as CT-induced inflammation [1,5]. Advances have also been made in understanding the signal transduction pathways involved in the expansion of suppressive myeloid cells. In this regard, a key role of signal transducer and activator of transcription 3 (STAT3) was reported in MDSCs' expansion and activation [20]. In addition, hematopoietic BM progenitors treated with tumor-derived supernatants exhibited an up-regulation of JAK2STAT3, increasing MDSCs' expansion in vitro [20]. C/EBP $\beta$ activation critically supports 
"emergency granulopoiesis", supporting granulocyte expansion, inhibiting apoptosis and producing a specific set of cytokines, such as IL-6, IL-10 and IL-12 [21]. Evidence obtained from studies on hepatocellular carcinoma (HCC) revealed a possible inter-connection between $C / E B P \beta$ and STAT3 in the context of MDSC expansion. In fact, the role of $C / E B P \beta$ as co-activator of STAT3 transcriptional activity was also reported [20]. Our group uncovered the role of retinoic acid-related orphan receptor C 1 (RORC1/ROR $\gamma)$, mainly expressed on immature myeloid cells during tumor-related inflammation. Interestingly, RORC1 induces $C / E B P \beta$ to sustain myeloid-derived suppressor cell expansion [22]. More recently, a new population of prometastatic TAMs, endowed with high rate of heme catabolism, was shown to be induced by an M-CSF-dependent activation of the transcription factor Nrf2 [23]. Therefore, in order to obtain a more comprehensive understanding of myeloid evolution in cancer carriers, we cannot ignore the integration of multistep mechanisms that alter the commitment of hematopoietic progenitors, their mobilization towards the periphery and the subsequent infiltration of tumors that expose myeloid cells to tumor-derived factors (TDFs) [8].

\section{Myeloid Cells Mobilization}

The prominent accumulation of immune-suppressive myeloid cells (i.e., MDSCs and TAMs) at the tumor site is the result of coordinated events that include the mobilization of myeloid progenitors from the bone marrow to the periphery and their subsequent recruitment at the tumor site [1]. Chemokine/chemokine receptor systems, adhesion molecules (VLA-4, CD44) and cytokines (G-CSF, SCF, FLT3-L) are critical orchestrators of hematopoietic stem and progenitor cells (HSPCs) mobilization. HSPCs' mobilization is induced clinically or experimentally in animal models by a wide variety of agents, such as cytokines (e.g., G-CSF), chemotherapeutic agents (e.g., cyclophosphamide) and small molecules which interfere with anchoring molecules (e.g., the CXCR4 antagonist AMD3100) [24].

We recently reported that M-CSF, in addition to inducing PU.1-driven myeloid differentiation, has a direct role in controlling the inducible form of nicotinamide phosphoribosyl transferase (iNAMPT) activity, catalyzing NAD biosynthesis [6]. Elevated expression of intracellular NAMPT (iNAMPT) in myeloid progenitors causes negative regulation of the $\mathrm{BM}$ retention axis of hematopoietic cells $\mathrm{C}-\mathrm{X}-\mathrm{C}$ motif chemokine receptor 4 (CXCR4), thus undocking these cells and allowing the mobilization of suppressor myeloid cells to the periphery [6]. In agreement with this, iNAMPT inhibition prevents MDSCs mobilization, reactivates specific antitumor immunity and enhances the antitumor activity of ICIs [6]. Various metabolic perturbations contribute to regulating these processes. As examples, glutamine starvation was found to be important for the upregulation of G-CSF and GMCSF, two well-known facilitators of myelopoiesis and the mobilization of hematopoietic progenitor cells [25], while hypercholesterolemia promoted bone marrow cell mobilization by perturbing the CXCL12/CXCR4 axis [26]. Evidence has been also provided that the hematopoietic-specific phospholipase C (PLC)- $\beta 2$ lipolytic enzyme promotes the mobilization of hematopoietic stem cells by decreasing their lipid raft-mediated bone marrow retention [27]. Complement component 3a receptor 1 (C3aR1) antagonists restrained neutrophil mobilization, and melanoma-bearing $\mathrm{C} 3 \mathrm{aR} 1$-deficient mice had reduced tumor growth and frequency of heme oxygenase 1 (HO-1) expressing monocytic blood precursors of $\mathrm{HO}-1^{+}$TAMs $[23,28]$. Blocking the C-C motif chemokine ligand 2 (CCL2)/C-C chemokine receptor type 2 (CCR2) pathway is also a rational approach to inhibit the accumulation of M-MDSCs and TAMs in the TME and to limit the mobilization of bone marrow monocytes into the blood stream, since the activation of CCR2 attenuates the CXCR4 anchoring signaling [29,30].

Once in the circulation, monocytes and MDSCs are actively recruited to primary and metastatic tumor sites. This process is regulated by chemokines produced by the tumor [31] The role of chemokines in the recruitment of myeloid cells to the tumor site influences specific antitumor immunity, metastasis formation and angiogenesis, thus playing a central 
role in tumor development and clinical response. These events have been extensively examined in recent works and do not represent the focus of the present work [32,33].

\section{Functional Heterogeneity of Tumor-Associated Myeloid Cells}

Tumor-infiltrating myeloid cells (e.g., macrophages, MDSCs and neutrophils) have a relevant role in establishing the intratumoral immunoprofile, which today represents a widely accepted prognostic index and therapeutic target [34,35]. It is, however, evident that myeloid cells in tumor tissues consist of a dynamic population characterized by considerable plasticity, which includes ontological and functional diverse subsets [36]. This "myeloid heterogeneity" is dictated by both local and systemic stimuli, able to affect specific genetic and epigenetic programs (Figures 2 and 3) [37].

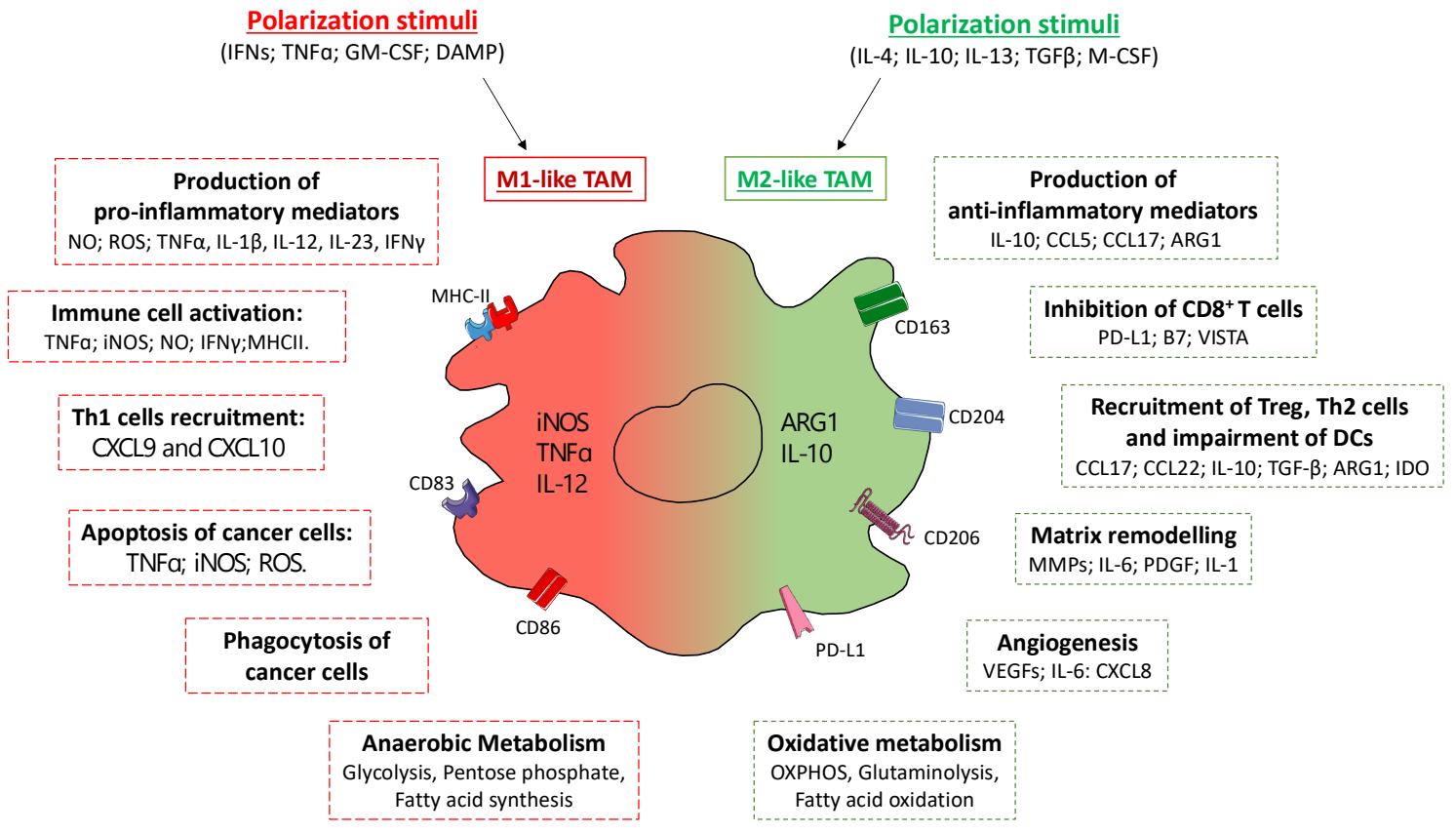

Figure 2. Influence of the polarization state of TAMs in the TME. Immunostimulatory signals (e.g., IFN, TNF $\alpha$, GM-CSF, DAMP) induce the inflammatory M1 phenotype of TAMs, which through the production of pro-inflammatory cytokines (e.g., TNF $\alpha$, IL-1 $\beta$, IL-12, IL-23, IFN $\gamma$ ), reactive oxygen species (ROS) and nitric oxide (NO) promote anticancer conditions. M1 TAMs also support the intratumoral homing and activation of $\mathrm{T}$ cells by producing specific chemotactic factors and favoring antigen presentation (e.g., CXCL9, CXCL10, MHC II). Furthermore, they exert tumoricidal activity by means of phagocytosis and direct killing of tumor cells, through cytotoxic mediators (e.g., TNF $\alpha$, NO, ROS). Conversely, M2-like macrophages are activated by immunomodulatory mediators with immunoregulatory properties (e.g., IL-4, IL-10, IL-13, TGF $\beta$, M-CSF) that favor tumor development. Indeed, M2-like TAMs secretespecific anti-inflammatory cytokines (e.g., IL-10) and chemokines (e.g., CCL5, CCL17, CCL22), which inhibit the specific response of T cells while supporting the recruitment of Treg and Th2 lymphocytes. They also support the formation of metastases, producing factors that promote angiogenesis (e.g., VEGFs, IL-6, CXCL8) and matrix remodeling (e.g., MMPs, IL-6, PDGF, IL-1). 


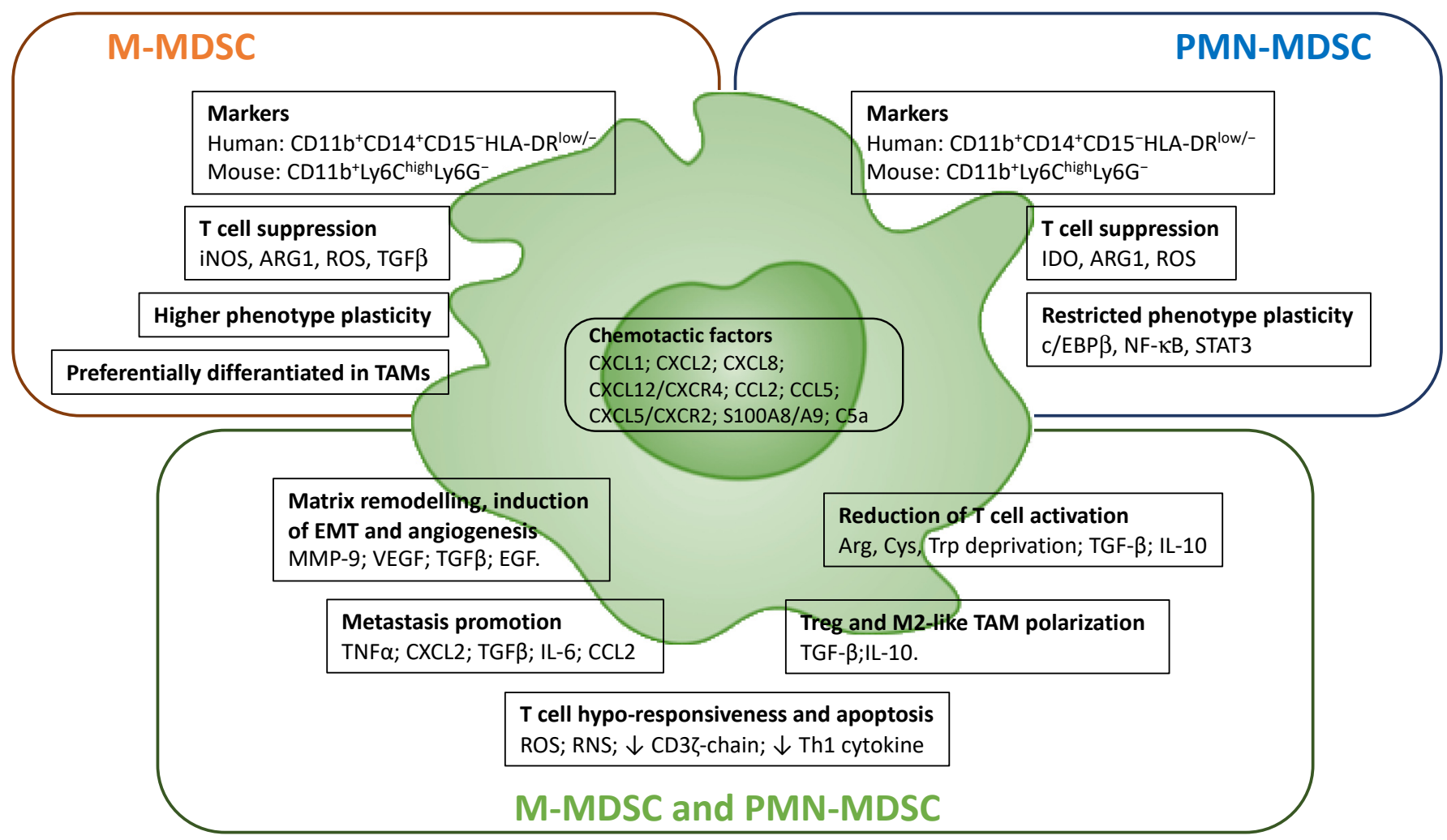

Figure 3. Phenotypic and functional traits of MDSCs. Human and murine markers are reported. MDSCs are recruited to the tumor site through chemotactic factors produced by the tumor. Inside the tumor, MDSCs exert their immunosuppressive functions by inhibiting the antitumor response of $\mathrm{T}$ lymphocytes, through various mechanisms. These include the production of immunosuppressive cytokines (e.g., IL-10, TGF $\beta$ ), the alteration of amino acid metabolism (Arg, arginine; Cys, cysteine; Trp, tryptophan) and peroxynitration of the $\mathrm{CD} 3 \zeta$ chain (by peroxynitration). MDSCs can also promote the spread of cancer cells by remodeling the extracellular matrix, promoting EMT and angiogenesis. The figure highlights the specific or shared characteristics of monocytic and granulocytic MDSC subsets. For abbreviations and details, see the text.

Recently, fate mapping experiments and high dimensional-analytic approaches with single-cell resolution have revealed a picture of the diversity within the myeloid compartment in several cancer types (i.e., lung cancer [38], melanoma [39], renal cancer [40], breast cancer [41], colon cancer [42,43]) dissecting the myeloid population into several distinct clusters, based on differential gene expression, localization in the TME, morphological features and functions [44]. Interestingly, the complexity of myeloid heterogeneity in the TME reflects the variability of therapeutic outcomes observed in cancer patients treated with immunotherapy [45]. Efforts are now converging on deeply understanding on how the activation state, localization and different phenotypes of myeloid cells contribute to the efficacy of anticancer therapies, focusing on the identification of prognostic and predictive markers useful for personalized therapies.

\subsection{Tumor Associated Macrophages (TAMs)}

TAMs include both resident and BM-derived macrophages and represent the most abundant myeloid population in the TME, where they adapt their functions in response to environmental cues [35]. This functional adaptation is oversimplified into the classical (M1) or alternative (M2) macrophage polarization model, with M1 referring to anti-tumorigenic and M2 to pro-tumorigenic macrophages (Figure 2) [46].

In particular, in response to endogenous TLR ligands (i.e., DAMPs) and interferons (IFNs), M1-polarized TAMs express anti-tumorigenic potential by releasing high levels of 
inflammatory mediators, such as tumor-necrosis factor (TNF)- $\alpha, \operatorname{IFN} \gamma$, nitric oxide (NO) via inducible NO synthase (iNOS), reactive oxygen species (ROS), and stimulate cytotoxic functions of NK cells and CD8 ${ }^{+} \mathrm{T}$ cells. Furthermore, their high phagocytic activity combined with the expression of major histocompatibility complex class II (MHCII), costimulatory molecules and T cell-recruiting chemokines (i.e., CXCL9 and CXCL10) make them strong promoters of Th1 responses [46,47]. Conversely, immunosuppressive (IL-10 and TGF $\beta$ ) and Th2 cytokines (IL-4, IL13), glucocorticoids and intratumor hypoxia promote M2-like TAMs polarization, mainly oriented towards the activation of Th2-type immune responses, extracellular matrix (ECM) remodeling and angiogenesis, mostly through the induction of arginase 1 (ARG1)- and IL-10-mediated and metalloprotease networks, promoting tumorigenesis and development [8].

TAMs are crucial promoters of the neoangiogenic switch in tumors, since their frequency correlates with vascular density in preclinical and human tumors and macrophage depletion strategies have been associated with reduced tumor angiogenesis in different preclinical models. Moreover, in response to hypoxia TAMs upregulate expression of hypoxia inducible factor (HIF)-1 $\alpha$ and secretion of angiogenic and lymphangiogenic factors, such as vascular endothelial growth factor A (VEGF-A), VEGF-C, IL-6, CXCL8 [48,49]. A distinct subset of TAMs expressing the TIE2 receptor (TIE2-expressing TAMs, TEMs) has been described to promote angiogenesis through release of proangiogenic and tissue-remodeling factors [50].

M2-like TAMs also contribute to the creation of an immunosuppressive TME via the expression of immune checkpoint ligands, such as PD-L1, PD-L2, B7 and VISTA, which directly inhibit T-cell activation/proliferation and simultaneously decrease essential costimulatory molecules, such as CD80 and CD86 [51]. Moreover, TAMs exert indirect effects on adaptive immune responses through the recruitment and activation of Tregs and Th2 cells, via the production of chemokines (i.e., CCL17 and CCL22) and anti-inflammatory molecules (i.e., IL-10, TGF- $\beta$, ARG1, IDO), as well as through the inhibition of DCs' maturation [52]. In the advanced stages of tumor development, M2-like TAMs facilitate the invasive behavior of cancer cell and metastatic progression through the release of various proteases involved in ECM digestion (i.e., members of the MMP and cathepsin families) [53], promoting the evasion of tumor-initiating cells, by expressing mediators of both cancer cell stemness (i.e., IL-6, PDGF, IL-1) [54] and proliferation (i.e., epidermal growth factor/EGF), and facilitating the epithelial-mesenchymal transition (EMT) [55].

In line with these protumor functions, preclinical and clinical data indicate a close relationship between high infiltration of M2-like TAMs and a poor prognosis in most types of tumor, such as pancreatic ductal adenocarcinoma (PDAC), glioblastoma, and bladder cancer $[35,55]$.

On the other hand, a correlation between TAMs' infiltration and improved cancerpatient survival has also been described in some cases, such as in endometrial cancer [56]. Such discordance can be attributed to the inter- and intra-tumor heterogeneity of TAMs, which may relate to different ontogeny, activation status and intratumor localization [8]. Interestingly, morphometric characterization of human TAMs purified from colorectal liver metastases revealed that large TAMs were associated with a poorer survival rate than small TAMs [42]. In breast cancer, the infiltration of immunosuppressive PD-L1 ${ }^{+} \mathrm{CD} 38^{+} \mathrm{TAMs}$ is more closely related to estrogen receptor-positive cancerous regions, thus limiting the success of immune checkpoint inhibitors [57].

In spite of the M1 vs. M2 oversimplification, intermediate stages of macrophage polarization can coexist in the same TME, although overall most TAMs closely resemble M2polarized macrophages [58]. Single-cell sequencing approaches have recently demonstrated the functional heterogeneity of TAMs embedded in different cancers [44,57,59], identifying up to 17 different TAM clusters, each characterized by a specific genetic profile. In liver cancer, Zhang et al. identified a specific subset of TAMs expressing high levels of ferroportinencoding gene SLC40A1, an iron exporter also involved in the release of pro-inflammatory cytokines, including IL-6, IL-23, and IL-1 $\beta$, via TLR-mediated signaling and associated with 
poor prognosis [59]. According to the role of iron metabolism in shaping a protumor TME, we recently described a specific subset of TAMs expressing a high level of heme oxygenase 1 enzyme (HO-1) and reported that the expansion of blood HO- $1^{+}$monocytes is associated with both increased frequency of HO- $1^{+}$TAMs and poor prognosis, in both preclinical fibrosarcoma and melanoma models, as well as in stage III-IV melanoma patients [23].

In line with this observation, transcriptional comparison of circulating monocytes derived from healthy subjects and oncological patients with breast and endometrial cancer, as well as characterization of their TAMs, revealed distinct transcriptional signatures, depending on cancer type. Furthermore, for each tumor type, the transcriptional signatures of the TAMs differed from the respective circulating monocytes [60].

TAMs mostly derive from circulating inflammatory monocytes and M-MDSCs, under the guidance of specific chemotactic pathways (i.e., CCL2, CCL5, CXCL12, system of complement) and intratumoral conditions (i.e., hypoxia) [61,62]. Nonetheless, it is now clear that tissue-resident macrophages are also indispensable regulators of the TME and contribute to the TAM population [63]. In malignant glioma, most TAMs derive from resident microglia, rather than circulating monocytes, and actively contribute to tumor progression [64]. In the murine pancreatic ductal adenocarcinoma (PDAC) model, tissueresident macrophages were found to expand during tumor progression and to promote fibrosis, a major barrier for PDAC therapy, while monocyte-derived TAMs had increased expression of genes associated with immunosuppression and antigen presentation [65].

Additionally, supporting the concept that TAMs harbor ontogenetically and functionally different macrophages, Loyher et al. demonstrated in lung cancer models that monocyte-derived TAMs contribute to tumor spread, while tissue-resident TAMs directly support the proliferation of cancer cells [66]. Moreover, tissue-resident self-renewing $\mathrm{CD}_{163^{+}} \mathrm{TIM}^{+}$macrophages in the metastatic omentum are described to provide protective niche for ovarian cancer stem cells and to promote their metastatic spread [67].

\subsection{Myeloid-Derived Suppressor Cells (MDSCs)}

MDSCs are a heterogeneous myeloid cell population characterized by the ability to suppress adaptive antitumor immune responses and directly contribute to both tumor growth and metastatic formation [68]. Currently, as a reflection of their lineage derivation, MDSCs are conventionally divided into two major monocytic and granulocytic subsets, based on their phenotypic and morphological features: monocytic MDSCs (M-MDSCs), which are identified as either human $\mathrm{CD} 11 \mathrm{~b}^{+} \mathrm{CD} 14^{+} \mathrm{CD} 15^{-} \mathrm{HLA}-\mathrm{DR} \mathrm{R}^{\text {low } /-}$ cells or mouse CD11b ${ }^{+}$Ly6 $\mathrm{C}^{\text {high }} \mathrm{Ly}_{6 \mathrm{G}}{ }^{-}$cells; and polymorphonuclear MDSCs (PMN-MDSCs) characterized as human $\mathrm{CD} 11 \mathrm{~b}^{+} \mathrm{CD} 14^{-} \mathrm{CD} 15^{+} \mathrm{HLA}-\mathrm{DR}{ }^{\text {low } /-}$ cells and mouse $\mathrm{CD} 11 \mathrm{~b}^{+} \mathrm{Ly}_{6 \mathrm{C}}{ }^{\text {low }} \mathrm{Ly}_{6 \mathrm{G}}{ }^{+}$ cells, respectively [62,69]. However, because MDSCs do not represent an actual subset of myeloid cells but rather a state of activation, understanding the complex nature of MDSC ${ }^{\prime}$ biology remains a great challenge.

In both tumor-bearing mice and cancer patients, MDSCs abundantly expand and accumulate in primary tumors and metastatic lesions, as well as in secondary lymphoid tissues, bone marrow and peripheral blood. Interestingly, frequency of circulating MDSCs is associated with poor clinical outcome in a variety of solid tumors $[62,68,70]$. Furthermore, low frequencies of circulating PMN-MDSCs and M-MDSCs are associated with higher overall survival in non-small cell lung cancer (NSCLC) patients treated with anti-PD-1 immunotherapy [71]. Accordingly, accumulation of a specific subset of circulating Tie $2^{\text {hi }}$ M-MDSCs that suppress antitumor T-cell response has been reported to correlate with a poor clinical outcome in NSCLC patients [72]. In patients with metastatic melanoma treated with ipilimumab, low frequencies of circulating M-MDSCs prior treatment were a predictor of better clinical outcome [73]. Thus, circulating levels of MDSCs can be used as a predictive marker for immune checkpoint blockade-based therapies in different tumors [68].

MDSCs contribute to tumor progression through different mechanisms, including the induction of angiogenesis and EMT, the secretion of matrix metallopeptidase 9 (MMP9), VEGF (in STAT3-dependent manner), transforming growth factor (TGF)- $\beta$, and growth 
factors (i.e., EGF), and the promotion of pre-metastatic niches and immune evasion (Figure 3) [62,74]. Several studies suggest that MDSCs are recruited in the pre-metastatic niche, through the CXCL1-, CXCL2-, and CXCL5-CXCR2 axis and in response to the pro-inflammatory proteins S100A8 and S100A9. Once in the site, MDSCs stimulate the migration of tumor cells by secreting TNF $\alpha$, CXCL2, TGF $\beta$, IL-6 and CCL2 [75]. MDSCs also enhance cancer stemness, since in vitro co-culture of MDSCs with primary ovarian cancer cells increased cancer cell stemness and promoted tumor sphere formation, increasing the incidence of tumor and metastatic foci in a xenograft model [54].

The main feature of MDSCs is their strong immunosuppressive activity [76]. The mechanisms of MDSC-induced immunosuppression include the production of reactive oxygen (ROS) and reactive nitrogen species (RNS) that cause T-cell hypo-responsiveness and apoptosis, affecting T-cell fitness by downregulating $\mathrm{CD} 3 \zeta$-chain expression and reducing cytokine secretion (Figure 3), as observed in pancreatic cancer and melanoma [62,76]. MDSCs-mediated T-cell hypo-responsiveness is also induced metabolically through deprivation from extracellular space of the amino acids arginine and cysteine, which are required for T-cell activation and proliferation, as well as through depletion of tryptophan by overexpression of indoleamine-pyrrole 2,3-dioxygenase (IDO) [76]. Moreover, MDSCs in TME produce large amounts of TGF $\beta$ and IL-10, which, respectively, exert anti-proliferative effects on T cells, inhibiting IL-2 secretion, and promote both the Treg differentiation and M2 polarization of TAMs [76,77].

At the cellular level, MDSCs derange immune checkpoint pathways and several studies have reported that high PD-L1 expression on blood MDSCs of cancer patients correlates with disease stage, acting as negative regulators of T and NK cell functions in TME [78]. Interestingly, M-MDSCs are reported to be more immunosuppressive compared to PMNMDSCs, both in tumor-bearing mice and in cancer patients, while tumor-infiltrating MMDSCs display a more potent suppressive activity than splenic M-MDSCs [79].

M-MDSCs predominantly suppress T-cell activation through the production of ARG1, iNOS and TGF $\beta$. Moreover, PMN-MDSCs are reported to primarily produce ROS and to exert antigen-specific immunosuppressive activities by cell-cell contact with $\mathrm{T}$ lymphocytes [76]. In addition, M-MDSCs exhibit higher cell plasticity compared to PMN-MDSCs, which is strictly controlled by specific transcription factors, such as $\mathrm{c} / \mathrm{EBP} \beta$, nuclear factor $\kappa \mathrm{B}(\mathrm{NF}-\mathrm{\kappa B})$ and STAT-3 [7]. Moreover, while in the TME M-MDSCs can differentiate into immunosuppressive TAMs [80], PMN-MDSCs are the predominant population in most cancers [81].

Although today we have a better understanding of both the immunosuppressive functions and metabolic traits of MDSCs, it remains to be established whether PMNMDSCs and M-MDSCs can be subdivided into smaller and distinguishable subsets. In fact, due to the shared expression of common surface markers, the distinction of MDSCs from monocytes and neutrophils is still a great challenge for the design of effective MDSCstargeted therapies.

PMN-MDSCs share the $\mathrm{CD} 11 \mathrm{~b}^{+} \mathrm{CD} 14^{-} \mathrm{CD} 15^{+}$phenotype with mature neutrophils and currently can be separated from peripheral blood only by the density gradient. Recent data obtained by RNA-sequencing and single-cell approaches have indicated several potential markers of MDSCs in cancer settings; however, their clinical utility and reliability need to be established. Condamine et al. demonstrated in patients with NSCLC and head and neck cancer that PMN-MDSCs have a distinct transcriptional profile characterized by the enrichment of genes involved in ER stress response, M-CSF, IL-6, IFN $\gamma$ and NF$\mathrm{KB}$, compared to neutrophils isolated from the same patients and from healthy donors. Moreover, this study identified lectin-type oxidized LDL receptor 1 (LOX1) as a specific surface marker of PMN-MDSCs in cancer patients [82]. In PDAC, transcriptomic analysis showed a distinct gene signature of M-MDSCs compared to monocytes, indicating STAT3 as a key regulator of monocytes reprogramming into M-MDSCs [79].

In a recent study, single-cell RNA-sequencing confirmed that both PMN-MDSCs and M-MDSCs isolated from spleens and tumors from breast cancer-bearing mice have a unique 
gene signature that differs from that of neutrophils and monocytes, though the expression of IL1 $\beta$, ARG2, CD84 and WFDC17 identified an overlapping signature common to PMNMDSCs and M-MDSCs [83]. Using single-cell analysis to compare tumor and normal tissue from early-stage NSCLC patients, Song et al. demonstrated the accumulation in tumor tissues of M-MDSCs expressing IL-10, CD14 and VEGF-A and PMN-MDSCs expressing IL-6, LOX1 and TGFß1 [84].

\subsection{Tumor-Associated Neutrophils (TANs)}

Neutrophils are short-lived, terminally differentiated and non-proliferative myeloid cells involved in proliferation and dissemination of tumor cells, as well as in immune suppression [13]. TANs are present in the TME of many solid tumors, and a large body of evidence has proved their prognostic significance in both peripheral blood and tumor tissues of cancer patients [85]. A higher percentage of TANs are generally associated with poorer response to chemotherapy and radiotherapy in several cancers, except for ovarian and gastric cancers [13]. Moreover, the neutrophil-to-lymphocyte ratio (NLR) in the blood is a prognostic survival marker in different tumors [86]. However, the exact correlation between NLR and/or TANs frequency with clinical outcome remain elusive and can be attributed, at least in part, to the functional plasticity of TANs. Indeed, TANs have been described to exhibit both anti- and pro-tumor features [87]; yet the full spectrum of transcriptional states of TANs, particularly in patients, remains unknown.

A recent time-of-flight mass spectrometry (CyTOF) analysis has identified seven mature neutrophil subsets in the blood of melanoma patients [88]. In a mouse model of lung adenocarcinoma, a specific subset of TANs characterized by high expression of the sialic acid binding Ig-like lectin $\mathrm{F}$ (Siglec $\mathrm{F}^{\text {high }}$ ) and associated with several pro-tumor functions was described to accumulate in TME [89].

Single-cell RNA sequencing of TANs from human and mouse lung tumors revealed five and six neutrophil subsets, respectively, with particular subsets of TANs expressing canonical neutrophil markers (i.e., MMP8, MMP9, S100A8, S100A9, ADAM8). Of relevance, TANs' subsets expressing inflammatory cytokines (i.e., CCL3, M-CSF) and expressing type I interferon-response genes are conserved between humans and mice [90,91].

The N1-N2 nomenclature has been used to distinguish neutrophil subpopulations with pro- vs. anti-tumor activity, respectively. N1 and N2 TANs are mainly defined based on their functional phenotypes; as specific cell surface markers have not yet been identified and apparently, they can mutually convert into each other [92]. N1 neutrophils are highly cytotoxic cells, display a more mature phenotype and high immune-activating ability. Conversely, N2 neutrophils are poorly cytotoxic, showing an immature phenotype and a high pro-angiogenic, pro-metastatic and immunosuppressive activity [86]. Recruitment of circulating neutrophils in tumor tissues is mainly regulated by CXCL1, CXCL2, CXCL8 and CXCL5 chemokines, the complement component anaphylatoxin C5a and tumor-derived oxysterols [93]. Tumor-derived factors dictate the phenotype and function of TANs. In particular, TGF $\beta$ has been demonstrated to induce a pro-tumor state characterized by high expression of arginase and strong immunosuppressive activity; on the other hand, IFN $\beta$, IFN $\gamma$ and GM-CSF stimulate TANs' polarization into an anti-tumor phenotype characterized by high cytotoxic activity [92,94].

TANs themselves can influence the TME landscape, both directly and indirectly. In both murine and human tumors, TANs support the proliferation and extravasation of tumor cells and angiogenesis, and hijack antitumor immunity [13]. Angiogenic TANs produce a high level of pro-angiogenic factors and matrix metalloproteinases (i.e., VEGF, MMP9) [86]. MMPs favor angiogenesis through remodeling the extracellular matrix, as well as cancer cell migration and invasion by stabilizing integrins [95]. In addition, TANs dampen T-cell-mediated antitumor immunity and support immune evasion through the production of the immunosuppressive cytokine TGF $\beta$, the upregulation of PD-L1, ROS production and the release of ARG1 [96,97]. 
Another important tumor-promoting mechanism is NETosis, a process by which neutrophils expel net-like structures (NETs) into the extracellular space. Cancer-primed neutrophils release NET during formation of spontaneous metastasis [98,99]. Mechanistically, during NETosis, neutrophils secrete the high mobility group box 1 (HMGB1) protein, thereby activating TLR9 signaling pathways, which promote cancer cells adhesion, proliferation and migration [100]. Moreover, in preclinical lung cancer, NET formation was reported to awake dormant cancer cells [101]. NETs can also act as a protective hull on cancer cells against cytotoxic immune T cell-mediated responses [102].

In contrast with these findings, TANs can also exert anti-tumor activities. They can produce high levels of ROS, NO and TNF $\alpha$ and express TNF-related apoptosis-inducing ligand (TRAIL), thus suppressing tumor cells proliferation. In response to the N1-polarizing cytokines IFN $\gamma$ and GM-CSF, TANs acquire antigen-presenting cell (APC) features and the ability to stimulate T-cell proliferation $[13,86]$.

\section{Pre-Clinical Targeting of Myeloid Cells in Cancer}

The growing understanding of the mechanisms underpinning the pro-tumoral activities of myeloid cells has paved the way for the development of multiple approaches to deplete or reprogram these cells in anti-tumor effectors [8]. Many of these preclinical approaches have been shown to exert significant anticancer effects and are now being evaluated in clinical trials (Figure 4).
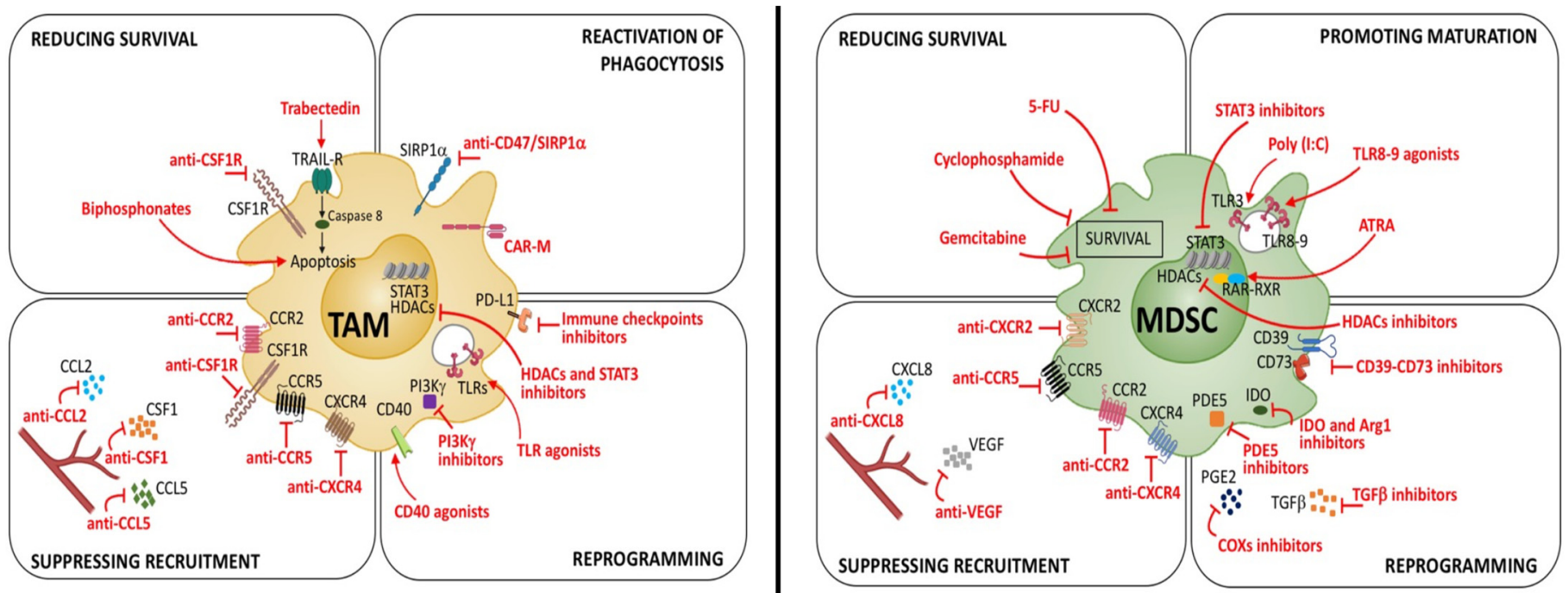

Figure 4. Main therapeutic approaches targeting TAM (left) or MDSC (right). Strategies targeting TAMs fall into four main categories: (1) direct killing of TAMs; (2) reactivation of their phagocytic activity; (3) inhibition of the recruitment of TAMs; and (4) re-education of TAMs towards a tumoricidal and immunostimulating phenotype. Similar to TAM, MDSC targeting can also be achieved through multiple approaches, including: (1) reducing their survival; (2) favoring their differentiation towards a mature myeloid effector phenotype; (3) inhibition of their recruitment, in both tumor tissues and secondary lymphoid organs; and (4) inhibition of their immunosuppressive functions. CSF1, colony stimulating factor 1; CSF1R, CSF1 receptor; PI3K $\gamma$, phosphoinositide 3-kinase- $\gamma$; HDAC, histone deacetylase; RARs-RXRs, retinoid-activated transcriptional regulators; ATRA, all trans retinoic acid; PDE5, phosphodiesterase; 5-FU, fluorouracil. For abbreviations and details, see the text.

\subsection{TAMs Targeting Approaches}

The neutralization of CSF1/CSF1R signaling by multiple approaches such as CSF1Rblocking antibodies and small molecules tyrosine kinase inhibitors has been demonstrated to efficiently deplete TAMs in several pre-clinical models such as fibrosarcoma, mesothelioma, colorectal, lung, prostate and pancreatic cancer [103]. Inhibiting the accumulation of TAMs by antibody-mediated CSF1R blockade was paralleled by both increased infiltration 
of $\mathrm{CD}^{+}$and $\mathrm{CD}^{+} \mathrm{T}$ cells and tumor growth inhibition [103]. Blocking CSF1R signaling can also reprogram macrophages in M1 effectors [104].

CCL2/CCR2 is a well-recognized axis driving the recruitment of both TAMs and MDSCs. Accordingly, CCR2 inhibitors reduce the infiltration of immunosuppressive myeloid cells limiting both primary tumor growth and metastasis spreading $[105,106]$. The anti-tumor effect was dependent on $\mathrm{CD} 8^{+} \mathrm{T}$ cells, supporting the concept that the depletion of tumor-associated myeloid cells mitigates immunosuppression and enhances the efficacy of T-cell targeting immunotherapies. The recruitment of myeloid cells is one of the protumoral activities exercised by IL-1 $\beta$, whose neutralization by an anti-IL-1 receptor (IL-1R) antibody curbed myeloid cell accumulation and tumor progression in mouse models of lung, breast and pancreatic tumors [107].

The marine-derived chemotherapeutic trabectedin, in addition of targeting tumor cells, selectively eliminates TAMs by activating caspase 8-dependent apoptosis through TRAIL [108]. An alternative strategy for TAMs' depletion exploits their high expression of scavenging receptors (e.g., CD163, MRC1/CD206, MARCO and STAB1) to selectively deliver cytotoxic drugs into TAMs. For example, in a mouse model of melanoma, a CD163 antibody conjugated with a lipid carrier loaded with doxorubicin selectively eliminated CD163 ${ }^{+}$TAMs, enabling tumor regression [109].

Thanks to the inherent plasticity of macrophages, many studies have developed approaches aimed at reprogramming TAMs in immunostimulatory and tumoricidal cells.

Agonist stimulation of macrophage activating receptors, including TLRs and the TNF receptor family member CD40, can trigger anti-tumor immune responses. For example, the injection of TLR7/TLR8 agonists in a subcutaneous model of melanoma rewired macrophages into proinflammatory cells increased T-cell infiltration. These anti-tumor effects were further enhanced by the combination with checkpoint inhibitors (anti-CTLA4 and anti-PD-1 antibodies) [110]. CD40 agonists are reported to induce cytotoxic activity by TAMs in different tumor models, including pancreatic cancer [111]. Noteworthily, the combination of anti-CSF1R antibody with the agonist anti-CD40 antibody led to a synergistic induction of proinflammatory macrophage polarization and the activation of $\mathrm{CD} 8^{+} \mathrm{T}$ cells, resulting in the regression of several transplanted tumor models (e.g., colon, sarcoma, and breast cancer) [112].

Phosphoinositide 3-kinase $\gamma(\mathrm{PI} 3 \mathrm{~K} \gamma)$, the most highly expressed PI3K isoform in myeloid cells is activated by many chemoattractant receptors and is associated with the recruitment of myeloid cells in murine and human tumors [113]. Moreover, in several tumor models, such as melanoma, lung, breast, head and neck carcinoma, genetic depletion or pharmacological inhibition of PI3K $\gamma$-induced proinflammatory gene expression in TAMs triggered the infiltration and activation of $\mathrm{CD} 8^{+} \mathrm{T}$ cells, which in turn reduced tumor growth and metastases [114,115].

Various evidence indicates that the activation of complement cascade supports tumorpromoting inflammation rather than anti-tumor immunity. In a squamous cell carcinoma model, TAMs promoted C5a production and the consequent C5aR-mediated M2polarization, resulting in $\mathrm{CD}^{+} \mathrm{T}$-cell inhibition and cancer progression [116]. According to this, blocking $\mathrm{C} 5 \mathrm{aR}$ signaling by the small molecule antagonist PMX-53 reprogrammed TAMs toward an M1 phenotype, enhancing the antitumor efficacy of PD-1/PD-L1 blockade [117]. Furthermore, in both transplanted and chemically induced sarcoma, genetic ablation of $\mathrm{C} 3$ and $\mathrm{C} 3 \mathrm{aR}$ was associated with reduced accumulation and pro-tumoral skewing of TAMs, along with increased T-cell activation and response to anti-PD-1 therapy [118].

A growing number of studies are showing that metabolic changes are associated with different activation states of macrophages [119]. Enhanced aerobic glycolysis and pentose phosphate pathway (PPP), along with a break in the Krebs cycle (TCA cycle) characterizing M1 macrophages, are causally linked to the expression of inflammatory genes. In contrast, M2 macrophages fuel their energy needs via oxidative phosphorylation (OXPHOS) and $\beta$-oxidation of fatty acids (FAO), generating high levels of ATP and acetylCoA that participates in TCA cycle and cholesterol biosynthesis [120]. Although these 
are oversimplified models, they support the hypothesis that reprogramming of selected metabolic traits could be a useful strategy to enhance TAMs' effector functions.

In lung and breast cancer models, TAMs showed an increased expression of key glycolytic enzymes (e.g., HK2, PFK, PKM2, and enolase1), suggesting that an accelerated glycolysis might be linked to the expression of pro-tumor activities [121]. Accordingly, dampening the glycolytic influx in TAMs by dichloroacetic acid significantly limited their migration and pro-metastatic ability [121]. Blocking glycolysis activity via HK2 inhibition also suppressed the vascular network formation and extravasation of tumor cells [122].

In multiple murine and human tumors, TAMs showed higher expression of the scavenger receptor CD36, associated with an increased uptake and breakdown of triglycerides by FAO. This metabolic commitment sustains the activation of STAT6, acting as a master coordinator of M2 gene expression [120]. Hence, targeting CD36 or FAO in macrophages might represent a potential strategy for their M1-reprogramming. Accordingly, in murine models of lymphoma and myeloma, either genetic ablation of CD36 in TAMs or FAO inhibition by etomoxir impaired macrophage pro-tumoral phenotype, hampering tumor growth and progression [120].

The production of $\alpha$-ketoglutarate $(\alpha \mathrm{KG})$ via glutaminolysis is a key molecular checkpoint that promotes both oxidative metabolisms, by feeding the TCA cycle, and M2-gene expression by supporting Jmjd3-dependent H3K27 demethylation [123]. In line, glutamine production in TAMs was found to be associated with a pro-tumoral M2-like phenotype. Accordingly, limiting the glutamine pool through the ablation of glutamine synthase or the inhibition of glutamate-ammonia ligase (GLUL) switches M2-like TAMs toward the M1-like phenotype [123,124].

Epigenetic reprogramming is another attractive strategy to reshape gene expression and functional TAM activation. It is known that the efficacy of many epigenetic drugs currently used in the clinic depends on their direct effects on tumor cells, as well as on their ability to modulate anti-tumor immunity [125]. In a breast cancer model, the class IIA HDAC inhibitor TMP195 was able to reprogram TAMs in inflammatory anti-tumor cells and synergized with inhibition of PD-1 in reducing tumor burden and metastasis [126]. In human and murine mesothelioma models, inhibitors of the histone methyl transferase EZH2 have been found to be associated with the recruitment of monocytes that differentiate in pro-tumoral TAMs, which impair the cytotoxic activity of adoptively transferred M1 macrophages $[127,128]$. Nevertheless, in a prostate cancer model, EZH2 inhibition in tumor organoids was able to induce stimulator of interferon genes (STING)-dependent activation of genes involved in antigen presentation, Th1 chemokine signaling and interferon response, including PD-L1 gene expression [129]. In keeping with this epigenetic reprograming of cancer cells, EZH2 inhibition was found to be associated with M1 TAMs reprogramming, increased recruitment of activated $\mathrm{CD}^{+} \mathrm{T}$ cells and enhanced response to PD-1 blockade in vivo [129]. These studies indicate that targeting both histone acetylation and methylation might be exploited to reshape the TME composition, although the effects of epigenetic modulators might vary across different tumor types.

Blocking phagocytosis checkpoints is an additional promising strategy to foster the anti-tumor activities of macrophages [130]. Indeed, upregulation of "don't eat me signals" by tumor cells is a well-recognized mechanism of immune evasion exploited by several cancers. The CD47-SIRP $\alpha$ axis is the most common "don't eat me" axis, whose neutralization by anti-CD47 or anti-SIRP $\alpha$ antibodies can enhance phagocytic clearance of cancer cells in many preclinical tumor models [131]. Noteworthily, CD47 blockade in tumor cells can also enhance cross-presentation of tumor antigens for CD8 ${ }^{+} \mathrm{T}$-cell activation, therefore improving anti-tumor effects [130]. Moreover, preclinical studies have demonstrated that neutralization of the CD47-SIRP $\alpha$ axis lowered the threshold for macrophage activation, enhancing the efficacy of various therapeutic antibodies such as rituximab in non-Hodgkin lymphoma, the anti-HER2 antibody in breast cancer, the anti-CD271 antibody in melanoma, and the anti-CD56 antibody in small-cell lung cancer [130]. Recently, the immune checkpoint inhibitor Hu5F9-G4, blocking CD47, was shown to synergize with 
rituximab to eliminate B-cell non-Hodgkin's lymphoma cells by enhancing macrophagemediated antibody-dependent cellular phagocytosis [132].

In addition to inhibiting PD1 ${ }^{+} \mathrm{T}$ effector cells, the expression of PD-L1 by cancer cells enables their evasion from macrophage-mediated phagocytosis. Although the mechanisms controlling expression and anti-phagocytosis function of PD-1 in TAMs are still unclear, the anti-tumor effect of blocking PD-1-PD-L1 axis in TAMs was definitely proved in mice lacking T, B and NK cells [133]. However, in transplant tumor models of melanoma, fibrosarcoma and colon cancer, genetic ablation of PD-1 in myeloid cells was associated with a remarkable anti-tumor effect, by favoring differentiation and functions of effector memory $\mathrm{T}$ cells [134]. Therefore, both phagocytosis-mediated and $\mathrm{T}$ cell-mediated anti-tumor immunity contribute to the therapeutic efficacy of PD-1-PD-L1 neutralization. In an attempt to enhance the phagocytosis capacity of macrophages, a CD47/PD-L1 bispecific antibody was developed and evaluated in mouse models, where it demonstrated higher efficacy than single anti-CD47 or anti-PDL1 treatment, both as monotherapy and in combinational therapy [135].

The leukocyte immunoglobulin-like receptor 1 (LILRB1) emerged as a phagocytosis inhibitory checkpoint that binds the $\beta 2$-microglobulin $(\beta 2 \mathrm{M})$ subunit of the histocompatibility complex class I (MHC-I). Preclinical studies pointed out that LILRB1 is highly expressed by TAMs and is responsible for the resistance of cancer cells expressing the common MHC-I component $\beta 2 \mathrm{M}$ to anti-CD47-induced phagocytosis [136]. Therefore, MHC class I-LILRB1 signaling axis, in addition to inhibit NK cells [137], provides an inhibitory axis whose neutralization could be exploited as anti-cancer approach.

Taking inspiration from chimeric antigen receptor (CAR)-T cells, endowing human macrophages with CAR represents an attractive strategy to overcome the inability of $\mathrm{T}$ cells to penetrate solid tumors. Macrophages genetically engineered to express a CAR specific to a tumor antigen are supposed to efficiently infiltrate solid tumors, where they could exert anti-tumor activity. Accordingly, primary human macrophages expressing a HER2-CAR have been generated and tested in vitro and in vivo in various preclinical xenograft models, demonstrating therapeutic efficacy, through increased phagocytosis of tumor cells and the conversion of bystander M2 macrophages to M1 polarization [138].

\subsection{MDSCs Targeting Approaches}

Elimination of MDSCs to alleviate immunosuppression and enhance anti-tumor immunity can be achieved by multiple strategies, including blocking their production during "emergency hematopoiesis", inhibiting their recruitment in both tumor tissues and secondary lymphoid organs and promoting their differentiation towards mature myeloid effector cells [62].

Blocking the CCL2/CCR2 axis was reported to be effective in reducing MDSCs and tumor growth in different preclinical models $[105,139]$. In addition, inhibitors of the CCR5 chemokine receptor have been shown to be effective in preventing MDSCs accumulation and immunosuppressive functions, both in mice [140] and in humans [141]. Moreover, genetic and pharmacological inactivation of CXCR2, which is the major chemotactic receptor for PMN-MDSCs and neutrophils recruitment into tumors, was demonstrated to be effective in reducing tumor-infiltrating PMN-MDSCs and improving the response to anti-PD-1 in different pre-clinical model, such as head and neck [142] and colon [143] cancer. In a colitis-associated cancer model, tadalafil, an inhibitor of phosphodiesterase-5 (PDE5), directly impaired MDSCs' infiltration in colonic tissue, reducing tumor development [144].

Anticancer drugs such as gemcitabine, 5-fluorouracil, docetaxel, doxorubicin and paclitaxel can also deplete MDSCs, thus enhancing the effector functions of T and NK cells [145]. Inducing apoptosis via death receptor 5 (DR5) agonists is a more tailored approach that exploits the upregulation of this TRAIL receptor by MDSCs [146]. The activation of liver $\mathrm{X}$ receptor (LXR) is another interesting strategy capable of selectively inducing MDSC apoptosis, relieving immunosuppression and enhancing anti-tumor immunity [147]. 
In several tumor models, prostaglandins E2 (PGE2) emerged as a key molecule driving both MDSCs' expansion and immunosuppressive activities [148]. Beyond several immunosuppressive molecules (e.g., IDO, IL-10, ARG1, VEGF and PD-L1), which are induced by PGE2 in MDSCs [149,150], we recently reported that tumor-derived PGE2 drives p50 NF- $k$ B-dependent epigenetic reprogramming of M-MDSCs, diverting their response to IFN $\gamma$ toward NO-mediated immunosuppression in preclinical models of fibrosarcoma and melanoma [7]. Although PGE2 synthesis can be efficiently blocked by cyclooxygenase 2 (COX2) inhibitors, their prolonged systemic use can lead to severe side effects, and thus alternative and safer approaches are needed. Blocking specific PGE2 receptors, such as EP1/EP2, may provide an alternative safer approach to boost specific anticancer immunity in patients [7]. Pharmacological inhibition of fatty acid transport protein 2 (FATP2) is an additional approach to impair PGE2 synthesis in PMN-MDSC, blocking their immunosuppressive activities and improving anti-CTLA-4 efficacy [151].

Activation of retinoic acid receptor through the all-trans retinoic acid (ATRA) represents an effective strategy to promote MDSCs' differentiation towards mature DCs and/or macrophages [152,153]. Noteworthy, in preclinical models of breast cancer, the combination of ATRA with VEGFR2 inhibitors and conventional chemotherapy increased the efficacy of anti-angiogenic therapy in association with a significant reduction in tumor growth [154].

TLR7 / 8 agonists also provide a strategy to induce MDSCs differentiation in anti-tumor effector mode. In a mouse model of colon cancer, the administration of R848 oriented the phenotype of MDSCs towards M1-like macrophages and improved the antitumor effect of oxaliplatin [155].

The transcription factor STAT3 is a key transcription factor active in both TAMs and MDSCs, whose targeting can rescue anti-tumor immune responses [156]. The conjugation of STAT3 siRNA or STAT3 decoy to cytosine-phosphorothioate-guanine (CpG) has been developed to tail the delivery of STAT3 inhibitor to myeloid cells. CpG-STAT3 inhibitors allowed the targeting of TLR9 expressing PMN-MDSCs, leading to their reprogramming in inflammatory anti-tumor cells in different hematological and solid tumor models [157].

Shaping MDSCs' metabolism represents another approach to myeloid cell reprogramming with the aim of obtaining anti-tumor functions. Both expansion and immunosuppressive activities of MDSCs are tightly associated with their metabolic commitment toward the CD36-mediated uptake of fatty acid and their subsequent oxidation. Accordingly, both CD36 deletion and pharmacological inhibition of FAO blocked the immunosuppressive functions of MDSCs, improving the efficacy of either immunotherapy or low-dose chemotherapy [120,158].

Finally, similar to TAMs, epigenetic modulators can influence MDSCs' differentiation and activities. Whereas treatments with the enhancer of zeste homolog 2 (EZH2) inhibitor GSK126 promoted the expansion of MDSCs, impairing antitumor immunity [159], entinostat, a class I histone deacetylase (HDAC) inhibitor, impaired MDSCs' immunosuppressive functions, improving the anti-tumor effects of anti-PD-1 antibodies [160].

\section{Clinical Advances in Targeting Tumor-Associated Myeloid Cells}

Tumors are dynamic and heterogeneous tissues that rely on the complex relationship and balance instated between cancer cells and infiltrating immune cells. While strategies that potentiate the activity of cytotoxic $\mathrm{CD} 8^{+} \mathrm{T}$ cells with immune checkpoint inhibitors (such as monoclonal antibodies (mAbs) against CTLA4, PD1 and PDL1) have shown efficacy in the treatment of cancers, such as melanoma and lung cancer, in most cases, cancer cells' polyclonality and immunosuppressive microenvironment mean that only a small fraction of patients fully respond to immunotherapy [161]. Several studies demonstrated that TAMs and MDSCs massively infiltrate cancer tissues and contribute to tumorigenesis by promoting angiogenesis, invasion and metastasis formation, cancer cell stemness, immunosuppression and resistance to therapy [162], pointing to TAMs and MDSCs as attractive targets for cancer immunotherapy. Here, we reported the most advanced clinical interventions targeting either TAMs or MDSCs. 


\subsection{Clinical Trials Targeting TAMs}

Pre-clinical observations on the tumor-promoting functions of M2-polarized TAMs are strongly supported by clinical evidence correlating the high frequency of infiltrating TAMs with poor overall survival (OS) in many cancers [8]. However, due to the functional plasticity of these cells, higher frequencies of TAMs have also been found to predict a good prognosis in colorectal cancer, ovarian carcinomas and follicular lymphoma, where an M1-like status of TAMs was observed [163,164]. In light of this dual facet of TAMs, different clinical approaches were suggested for their manipulation in cancer therapy. These latter converge into two main approaches: (1) abrogating TAM enrichment (Table 1) and (2) re-educating immunosuppressive M2-like TAMs into M1-like immunostimulatory and tumoricidal cells (Table 2). These two perspectives were approved for clinical trials by the Food and Drug Administration (FDA) agency. Here, we will focus on the most advanced strategies, as summarized in Tables 1 and 2.

\subsubsection{Abrogating TAM Enrichment}

As mentioned, a high frequency of TAMs in the tumor microenvironment is associated with both bad prognosis and immunosuppression. Therefore, therapeutic strategies to hamper their enrichment have targeted: (i) TAMs depletion and/or (ii) inhibition of their recruitment into TME (Table 1).

\section{Depleting TAMs}

A main approach to deplete TAMs is the inhibition of colony-stimulating factor 1 receptor (CSF-1R) which, interacting with its CSF-1 or IL-34 ligands, plays a critical role in the survival, differentiation and maturation of macrophages [165]. Several small molecule inhibitors or blocking antibodies were exploited to reduce the survival of macrophages. Pexidartinib (PLX3397) was approved in a phase 3 trial for the treatment of tenosynovial giant cell tumor (TGCT), which is characterized by high infiltration of CSF1R ${ }^{+}$macrophages [166]. Pexidartinib is now under clinical evaluation for the treatment of breast, pancreatic and colorectal cancer in combination with other chemo- and/or immuno-therapies (see Table 1). Other CSF1R ${ }^{+}$inhibitors include: the c-Fms inhibitor edicotinib (JNJ-40346527), in the treatment of prostate cancer (ClinicalTrials: NCT03177460); the kinase inhibitor vimseltinib, in the treatment of sarcomas, as well as TGCT (NCT04242238, NCT05059262). A number of monoclonal antibodies (mAbs) blocking the CSF1/CSF1R axis are under clinical development: cabiralizumab (FPA008) for the treatment of pancreatic, non-small cell lung and renal cell cancer, in addition to TCGT and melanoma (see Table 1); emactuzumab (RG7155) in combination with bevacizumab (anti-VEGF $\mathrm{mAb}$ ) and paclitaxel is under evaluation for the treatment of ovarian cancer (NCT02923739); MCS110 mAb was instead approved for a phase $1 / 2$ clinical trial for the treatment of melanoma in combination with BRAF/MEK inhibitors (NCT03455764). However, clinical phase 2 studies of pexidartinib in recurrent glioblastoma [167] and MCS-110 in triple negative breast cancer [168] indicated that these agents did not improve the outcome of patients, although therapies were well-tolerated. This suggests that patient stratification could be a necessary assessment in future studies. 
Table 1. Summarized list of completed or active clinical trials targeting TAMs enrichment.

\begin{tabular}{|c|c|c|c|c|c|c|}
\hline Strategy & Target & Drug Name & Combined Therapy & Disease & Clinical Trial & Clinical Benefit Rate \\
\hline \multirow{17}{*}{$\begin{array}{l}\text { TAM } \\
\text { depletion }\end{array}$} & \multirow{17}{*}{ CSF1/CSF1R } & \multirow{4}{*}{ Pexidartinib } & Single agent & $\begin{array}{l}\text { Tenosynovial Giant Cell } \\
\text { Tumor (TGCT) }\end{array}$ & NCT02371369 & Overall response: $53 \%$ \\
\hline & & & $\begin{array}{l}\text { Paclitaxel } \\
\text { Single agent }\end{array}$ & $\begin{array}{l}\text { Advanced solid tumors } \\
\text { Acute Myeloid Leukemia }\end{array}$ & $\begin{array}{l}\text { NCT01525602 } \\
\text { NCT01349049 }\end{array}$ & $\begin{array}{l}\text { Clinical benefit: } 40 \% \\
\text { Overall response: } 21 \%\end{array}$ \\
\hline & & & Durvalumab & $\begin{array}{l}\text { Advanced Pancreatic and } \\
\text { Colorectal Cancer }\end{array}$ & NCT02777710 & No results posted \\
\hline & & & Eribulin & Metastatic Breast Cancer & NCT01596751 & Not yet reported \\
\hline & & PLX7486 & Single agent & $\begin{array}{l}\text { Advanced solid tumors, } \\
\text { TGCT }\end{array}$ & NCT01804530 & No results posted \\
\hline & & BLZ945 & Spartalizumab & Advanced solid tumors & NCT02829723 & Not yet reported \\
\hline & & Edicotinib & Daratumumab & Advanced Prostate Cancer & NCT03177460 & Not yet reported \\
\hline & & ARRY-382 & Pembrolizumab & Advanced Solid Tumors & NCT02880371 & No results posted \\
\hline & & \multirow{3}{*}{ IMC-CS4 } & GVAX, Pembrolizumab & Pancreatic Cancer & NCT03153410 & Not yet reported \\
\hline & & & $\begin{array}{l}\text { Durvalumab, } \\
\text { Tremelimumab }\end{array}$ & Advanced Solid Tumors & NCT02718911 & Disease Control: $33.3 \%$ \\
\hline & & & Vemurafenib, Cobimetinib & Melanoma & NCT03101254 & Not yet reported \\
\hline & & Emactuzumab & Bevacizumab, Paclitaxel & $\begin{array}{l}\text { Ovarian, Fallopian Tube or } \\
\text { Peritoneal Cancer }\end{array}$ & NCT02923739 & Not yet reported \\
\hline & & \multirow{3}{*}{ Cabiralizumab } & Single agent & $\begin{array}{l}\text { Tenosynovial Giant Cell } \\
\text { Tumor }\end{array}$ & NCT02471716 & Not yet reported \\
\hline & & & $\begin{array}{l}\text { Nivolumab } \\
\text { Nivolumab, chemotherapies }\end{array}$ & $\begin{array}{l}\text { Advanced Solid Tumors } \\
\text { Advanced Pancreatic Cancer }\end{array}$ & $\begin{array}{l}\text { NCT02526017 } \\
\text { NCT03336216 }\end{array}$ & $\begin{array}{l}\text { Not yet reported } \\
\text { Not yet reported }\end{array}$ \\
\hline & & & Sotigalimab, Nivolumab & $\begin{array}{l}\text { Melanoma, NSC Lung, } \\
\text { Renal Cell Carcinoma }\end{array}$ & NCT03502330 & Not yet reported \\
\hline & & \multirow{2}{*}{ Vimseltinib } & Avelumab & $\begin{array}{l}\text { Advanced or Metastatic } \\
\text { Sarcomas }\end{array}$ & NCT04242238 & Not yet reported \\
\hline & & & Single agent & $\begin{array}{l}\text { Tenosynovial Giant Cell } \\
\text { Tumor }\end{array}$ & NCT05059262 & Not yet reported \\
\hline
\end{tabular}


Table 1. Cont.

\begin{tabular}{|c|c|c|c|c|c|c|}
\hline Strategy & Target & Drug Name & Combined Therapy & Disease & Clinical Trial & Clinical Benefit Rate \\
\hline & & AMG 820 & Pembrolizumab & Advanced Solid Tumor Cancer & NCT02713529 & Overall Response: $34 \%$ \\
\hline & & \multirow[b]{2}{*}{ Axatilimab } & Durvalumab & \multirow{2}{*}{$\begin{array}{l}\text { Solid Tumors } \\
\text { Unresectable } \\
\text { Cholangiocarcinoma }\end{array}$} & NCT03238027 & Not yet reported \\
\hline & & & Durvalumab & & NCT04301778 & Not yet reported \\
\hline & & & Spartalizumab & $\begin{array}{l}\text { Breast and Pancreatic Cancer, } \\
\text { Melanoma }\end{array}$ & NCT02807844 & Overall Response: $27 \%$ \\
\hline & & MCS110 & $\begin{array}{l}\text { Carboplatin, } \\
\text { Gemcitabine }\end{array}$ & $\begin{array}{l}\text { Advanced Triple-Negative } \\
\text { Breast Cancer }\end{array}$ & NCT02435680 & Clinical benefit: $29.4 \%$ \\
\hline & & & Dabrafenib, Trametinib & Melanoma & NCT03455764 & Not yet reported \\
\hline & & TPX-0022 & Single agent & Advanced Solid Tumor & NCT03993873 & Not yet reported \\
\hline & \multirow[t]{2}{*}{ Whole cell } & \multirow[t]{2}{*}{ Biphosphonates } & Single agents & Primary Breast Cancer & NCT00127205 & Overall survival: $92.4 \%$ \\
\hline & & & Denosumab & Metastatic Breast Cancer & NCT00091832 & Not yet reported \\
\hline & \multirow{3}{*}{ Caspase 8} & \multirow{3}{*}{ Trabectedin } & Low-dose radiotherapy & $\begin{array}{l}\text { Advanced/Metastatic } \\
\text { Sarcomas }\end{array}$ & NCT05131386 & Not yet reported \\
\hline & & & Olaratumab & Advanced Soft-tissue Sarcoma & NCT03985722 & Not yet reported \\
\hline & & & Single agent & $\begin{array}{l}\text { Malignant Pleural } \\
\text { Mesothelioma }\end{array}$ & NCT02194231 & Not yet reported \\
\hline \multirow{7}{*}{$\begin{array}{l}\text { Inhibition of TAM } \\
\text { recruitment }\end{array}$} & \multirow{7}{*}{ CCR2/CCL2 } & \multirow{3}{*}{ Carlumab } & Single agent & \multirow{3}{*}{$\begin{array}{l}\text { Metastatic Castrate-Resistant } \\
\text { Prostate Cancer } \\
\text { Solid Tumors } \\
\text { Solid Tumors }\end{array}$} & NCT00992186 & Stable disease: $2.4 \%$ \\
\hline & & & Single agent & & NCT00537368 & No results posted \\
\hline & & & Chemotherapies & & NCT01204996 & Overall response: $38 \%$ \\
\hline & & Plozalizumab & $\begin{array}{l}\text { Single agent } \\
\text { ICIs }\end{array}$ & $\begin{array}{l}\text { Bone Metastatic Solid Tumors } \\
\text { Advanced Melanoma }\end{array}$ & $\begin{array}{l}\text { NCT01015560 } \\
\text { NCT02723006 }\end{array}$ & $\begin{array}{l}\text { Overall response: } 14 \% \\
\text { Interrupted }\end{array}$ \\
\hline & & \multirow[t]{2}{*}{ PF-04136309 } & $\begin{array}{l}\text { Nab-paclitaxel, } \\
\text { Gemcitabine }\end{array}$ & $\begin{array}{l}\text { Metastatic Pancreatic Ductal } \\
\text { Adenocarcinoma }\end{array}$ & NCT02732938 & Objective response: $23 \%$ \\
\hline & & & FOLFIRINOX & Pancreatic Neoplasms & NCT01413022 & Objective response: $49 \%$ \\
\hline & & CCX872-B & Single agent & Pancreatic Adenocarcinoma & NCT02345408 & Overall survival: $29 \%$ \\
\hline
\end{tabular}


Table 1. Cont.

\begin{tabular}{|c|c|c|c|c|c|c|}
\hline Strategy & Target & Drug Name & Combined Therapy & Disease & Clinical Trial & Clinical Benefit Rate \\
\hline & \multirow{4}{*}{ CCR2-CCR5 } & \multirow{4}{*}{ BMS-813160 } & $\begin{array}{l}\text { Nivolumab, } \\
\text { Chemotherapies }\end{array}$ & \multirow{2}{*}{$\begin{array}{l}\text { Pancreatic Ductal } \\
\text { Adenocarcinoma } \\
\text { Pancreatic Ductal } \\
\text { Adenocarcinoma }\end{array}$} & NCT03496662 & Not yet reported \\
\hline & & & Nivolumab, GVAX & & NCT03767582 & Not yet reported \\
\hline & & & $\begin{array}{l}\text { Chemotherapy, } \\
\text { Nivolumab }\end{array}$ & Advanced Solid Tumors & NCT03184870 & Not yet reported \\
\hline & & & Nivolumab, BMS-986253 & $\begin{array}{l}\text { NSC Lung and } \\
\text { Hepatocellular Carcinoma }\end{array}$ & NCT04123379 & Not yet reported \\
\hline & \multirow{6}{*}{ CCR5/CCL5 } & \multirow[b]{2}{*}{ Maraviroc } & Pembrolizumab & \multirow{2}{*}{$\begin{array}{l}\text { Metastatic Colorectal Cancer } \\
\text { Metastatic Colorectal and } \\
\text { Pancreatic Cancer }\end{array}$} & NCT03274804 & Disease Control: $5.3 \%$ \\
\hline & & & Ipilimumab, Nivolumab & & NCT04721301 & Not yet reported \\
\hline & & Vicriviroc & Pembrolizumab & $\begin{array}{l}\text { Advanced Colorectal } \\
\text { Cancers }\end{array}$ & NCT03631407 & No results posted \\
\hline & & \multirow{3}{*}{ Leronlimab } & Single agent & \multirow{3}{*}{$\begin{array}{l}\text { Advanced Solid Tumors } \\
\text { Metastatic Triple-Negative } \\
\text { Breast Carcinoma } \\
\text { Metastatic Triple-Negative } \\
\text { Breast Carcinoma }\end{array}$} & NCT04504942 & Not yet reported \\
\hline & & & Single agent & & NCT04313075 & Not yet reported \\
\hline & & & Carboplatin & & NCT03838367 & Not yet reported \\
\hline & \multirow{9}{*}{ CXCR4/CXCL12 } & \multirow{3}{*}{ LY2510924 } & Sunitinib & \multirow{3}{*}{$\begin{array}{l}\text { Metastatic Renal Cell } \\
\text { Carcinoma } \\
\text { Extensive Stage Small Cell } \\
\text { Lung Carcinoma } \\
\text { Solid Tumors }\end{array}$} & NCT01391130 & Insufficient Efficacy \\
\hline & & & Carboplatin, Etoposide & & NCT01439568 & Insufficient Efficacy \\
\hline & & & Durvalumab & & NCT02737072 & Interrupted \\
\hline & & \multirow{3}{*}{ Motixafortide } & \multirow{3}{*}{$\begin{array}{l}\text { Cemiplimab, } \\
\text { Chemotherapy } \\
\text { Pembrolizumab } \\
\text { Pembrolizumab, } \\
\text { Onivyde }^{\circledR}\end{array}$} & Pancreatic Adenocarcinoma & NCT04543071 & Not yet reported \\
\hline & & & & Metastatic Pancreatic Cancer & NCT02907099 & Not yet reported \\
\hline & & & & Metastatic Pancreatic Cancer & NCT02826486 & Disease Control: $77 \%$ \\
\hline & & \multirow{3}{*}{ Plerixafor } & Cemiplimab & \multirow{3}{*}{$\begin{array}{l}\text { Metastatic Pancreatic Cancer } \\
\text { Pancreatic, Ovarian and } \\
\text { CRC Cancers } \\
\text { Head and Neck Cancer }\end{array}$} & NCT04177810 & Not yet reported \\
\hline & & & Single agent & & NCT02179970 & Stable disease: $57 \%$ \\
\hline & & & Pembrolizumab & & NCT04058145 & Interrupted \\
\hline
\end{tabular}


Table 2. Summarized list of completed or active clinical trials targeting TAMs functions.

\begin{tabular}{|c|c|c|c|c|c|}
\hline Strategy & Target & Drug Name & Combined Therapy & Disease & Clinical Trial \\
\hline \multirow{18}{*}{$\begin{array}{l}\text { Reprogramming TAM } \\
\text { polarization }\end{array}$} & \multirow{18}{*}{ TLRs } & GSK1795091 & GSK3174998, Pembrolizumab & Advanced Solid Tumors & NCT03447314 \\
\hline & & & 5-fluorouracil & Squamous Cell Carcinoma & NCT03370406 \\
\hline & & & Abraxane & Advanced Breast Cancer & NCT00821964 \\
\hline & & & Single agent & Breast Cancer with Skin Metastases & NCT00899574 \\
\hline & & \multirow{2}{*}{$852 \mathrm{~A}$} & Single agent & $\begin{array}{l}\text { Unresectable Metastatic Cutaneous } \\
\text { Melanoma }\end{array}$ & NCT00189332 \\
\hline & & & Single agent & $\begin{array}{l}\text { Breast, Ovarian, Endometrial, Cervical } \\
\text { Cancers }\end{array}$ & NCT00319748 \\
\hline & & Resiquimod & gp100 and MAGE3 peptide vaccine & Melanoma & NCT00960752 \\
\hline & & \multirow{3}{*}{ Motolimod } & Durvalumab, Doxorubicin & $\begin{array}{l}\text { Recurrent, Platinum-resistant Ovarian } \\
\text { Cancer }\end{array}$ & NCT02431559 \\
\hline & & & Nivolumab & Head and Neck Cancer & NCT03906526 \\
\hline & & & Cetuximab & $\begin{array}{l}\text { Metastatic Head and Neck Squamous } \\
\text { Carcinoma }\end{array}$ & NCT01836029 \\
\hline & & IMO-2055 & FOLFIRI, Cetuximab & Colorectal Cancer & NCT00719199 \\
\hline & & \multirow{3}{*}{ Tilsotolimod } & Ipilimumab & Metastatic Melanoma & NCT03445533 \\
\hline & & & Single agent & Malignant Melanoma & NCT04126876 \\
\hline & & & Ipilimumab, Pembrolizumab & Metastatic Melanoma & NCT02644967 \\
\hline & & \multirow{4}{*}{ CMP-001 } & Pembrolizumab & $\begin{array}{l}\text { Head and Neck Squamous Cell } \\
\text { Carcinoma }\end{array}$ & NCT04633278 \\
\hline & & & Nivolumab & Advanced Melanoma & NCT04698187 \\
\hline & & & Stereotactic body radiotherapy & $\begin{array}{l}\text { Early-Stage Triple Negative Breast } \\
\text { Cancer }\end{array}$ & NCT04807192 \\
\hline & & & Atezolizumab, Radiotherapy & Non-Small Cell Lung Cancer & NCT03438318 \\
\hline
\end{tabular}


Table 2. Cont.

\begin{tabular}{|c|c|c|c|c|c|}
\hline Strategy & Target & Drug Name & Combined Therapy & Disease & Clinical Trial \\
\hline & \multirow{11}{*}{ CD40 } & \multirow{3}{*}{ Selicrelumab } & Atezolizumab & Advanced Solid Tumors & NCT02304393 \\
\hline & & & Nab-paclitaxel, Gemcitabine & Pancreatic Cancer & NCT02588443 \\
\hline & & & Emactuzumab & Advanced Solid Tumors & NCT02760797 \\
\hline & & SEA-CD40 & Pembrolizumab, Gemcitabine & Advanced Solid Tumors & NCT02376699 \\
\hline & & \multirow{3}{*}{ Sotigalimab } & Doxorubicin & Soft Tissue Sarcoma & NCT03719430 \\
\hline & & & Pembrolizumab & Metastatic Melanoma & NCT02706353 \\
\hline & & & Single agent & Pediatric CNS Tumors & NCT03389802 \\
\hline & & \multirow{2}{*}{ CP-870,893 } & Tremelimumab & Metastatic Melanoma & NCT01103635 \\
\hline & & & Paclitaxel + Carboplatin & Advanced Solid Tumors & NCT00607048 \\
\hline & & CDX-1140 & Pembrolizumab, Chemotherapy & Advanced Solid Tumors & NCT03329950 \\
\hline & & ABBV-428 & Nivolumab & Advanced Solid Tumors & NCT02955251 \\
\hline & \multirow{3}{*}{$\mathrm{PI} 3 \mathrm{~K} \gamma$} & \multirow{3}{*}{ Eganelisib } & Nivolumab & Advanced Solid Tumors & NCT02637531 \\
\hline & & & Etrumadenant, doxorubicin, & $\begin{array}{l}\text { Triple-Negative Breast and Ovarian } \\
\text { Cancer }\end{array}$ & NCT03719326 \\
\hline & & & Nivolumab & Advanced Urothelial Carcinoma & NCT03980041 \\
\hline & \multirow{2}{*}{ HDACs } & \multirow{2}{*}{ Tucidinostat } & Cisplatin & Metastatic Triple-negative Breast Cancer & NCT04192903 \\
\hline & & & Toripalimab & Advanced Cervical Cancer & NCT04651127 \\
\hline & STAT3 & TTI-101 & Single agent & Advanced Solid Tumors & NCT03195699 \\
\hline \multirow{6}{*}{ Re-activation of phagocytosis } & \multirow{6}{*}{$\mathrm{CD} 47 / \mathrm{SIRP} 1 \alpha$} & \multirow{6}{*}{ Magrolimab } & Cetuximab & Advanced Solid Tumors & NCT02953782 \\
\hline & & & Avelumab & Ovarian Cancer & NCT03558139 \\
\hline & & & Dinutuximab & Neuroblastoma, Osteosarcoma & NCT04751383 \\
\hline & & & Docetaxel & Advanced Solid Tumors & NCT04827576 \\
\hline & & & Pactiltaxel, Nab-paclitaxel & Metastatic Triple-Negative Breast Cancer & NCT04958785 \\
\hline & & & Pembrolizumab, Chemotherapies & $\begin{array}{l}\text { Head and Neck Squamous Cell } \\
\text { Carcinoma }\end{array}$ & NCT04854499 \\
\hline
\end{tabular}


Table 2. Cont.

\begin{tabular}{|c|c|c|c|c|c|}
\hline Strategy & Target & Drug Name & Combined Therapy & Disease & Clinical Trial \\
\hline & & \multirow{3}{*}{ TTI-621 } & Rituximab, Nivolumab & Solid Tumors & NCT02663518 \\
\hline & & & ICIs, Radiation, T-Vec & Advanced Solid Tumors & NCT02890368 \\
\hline & & & Doxorubicin & Metastatic High-Grade Leiomyosarcoma & NCT04996004 \\
\hline & & CC-90002 & Rituximab & $\begin{array}{l}\text { Advanced Solid and Hematologic } \\
\text { Cancer }\end{array}$ & NCT02367196 \\
\hline $\begin{array}{l}\text { Genetically } \\
\text { engineering TAM }\end{array}$ & $\begin{array}{l}\text { HER2-directed } \\
\text { CAR-M }\end{array}$ & CT-0508 & Single agent & HER2-overexpressing Solid Tumors & NCT04660929 \\
\hline
\end{tabular}




\section{Inhibition of TAMs Recruitment}

A number of cytokines and chemokines regulate the trafficking of bone marrowderived monocytes into the tumor microenvironment where they differentiate into TAMs. CCL2, which interacts with its receptor CCR2, has gained clinical relevance. In several cancers, CCL2 levels correlate with TAM frequency, metastasis score and poor survival [169].

At present, two main drugs that target CCR2 are under clinical evaluation: the CCL2-blocking monoclonal antibody carlumab (CNTO-888) and the small molecule CCR2inhibitor PF-04136309. Carlumab showed a partial reduction in CCL2 levels, with good tolerance in patients affected by different solid tumors, while it did not show significant efficacy in a phase II study on castration-resistant prostate cancer patients [170]. In advanced pancreatic cancer patients, the PF-04136309 inhibitor in combination with FOLFIRINOX exerted an objective anti-tumor effect, as compared with FOLFIRINOX alone [171]. Recently, a tolerability study of CCR2-blocking antibody plozalizumab (MLN1202) was performed on melanoma patients (NCT02723006).

CCL5/CCR5 is another important axis for the recruitment of TAMs into TME [172]. Different CCR5 antagonists, formerly developed for the treatment of HIV, are under clinical studies for cancer therapy. These include: leronlimab (PRO 140), which is currently in a phase 1 study, either in combination with carboplatin or alone, for the treatment of triplenegative breast cancer [172], and in a phase 2 study for the treatment of solid metastatic tumors (NCT0450494); maraviroc and vicriviroc, plus pembrolizumab, were used in a phase 1 clinical trial in the treatment of metastatic colorectal cancer with a good toxicity profile (NCT03274804, NCT03631407). Furthermore, BMS-813160, a CCR2/CCR5 dual antagonist, has been studied in combination treatments in non-small cell lung cancer (NSCLC), hepatocellular carcinoma (HCC), and pancreatic ductal adenocarcinoma (NCT04123379, NCT03496662).

The CXCL12 chemokine and its receptor, CXCR4, represent another important gate for the mobilization and recruitment of monocyte/macrophage into TME [173]. Increased CXCR4 expression was associated with disease progression of NSCLC, while CXCL12 was increased after radiotherapy in different tumors [174,175]. Plerixafor (AMD3100), a CXCR4 antagonist, was used in combination with chemo-radiotherapy for the treatment of glioblastoma and studied for its ability to prevent the recurrence of glioblastoma after radiation treatment (NCT03746080). Another CXCR4 antagonist, motixafortide (BL-8040), combined with pembrolizumab in metastatic pancreatic cancer, is being evaluated (NCT02907099).

\subsubsection{Re-Education of TAMs}

Although direct depletion of TAMs was shown to have effective antitumor functions, the heterogeneity of TAMs and in particular the antitumor potency of M1-like TAMs appears as a promising therapeutic option (Table 2).

\section{Targeting TAM Polarization}

TLRs are pattern recognition receptors that potently activate innate immune responses, favoring the pro-inflammatory polarization of macrophages. Therefore, several TLR agonists are under extended clinical evaluation. Of relevance, bacilli calmette guerin (BCG) is the first FDA-approved TLR agonist for the treatment of high-grade nonmuscle-invasive bladder cancer. It is capable to stimulate TLR2 and TLR4, promoting a conversion of TAMs toward an M1-like status [176]. Imiquimod, a TLR7 agonist, showed a partial response associated with changes in the inflammatory profile in breast cancer patients with skin metastasis [177]. 852A is another TLR7 agonist which has been tested for the treatment of melanoma and gynecological cancers [178]. The TLR8 agonist motolimod (VTX-2337), in combination with cetuximab, showed a significant benefit in human papilloma virus (HPV)-positive head and neck cancer patients [179]. IMO-2055 (TLR9 agonist) were evaluated in the treatment of colorectal cancer (CRC) and NSCLC patients, in combination with standard therapies showing a potential antitumoral effects, as well as a good tolerability (NCT00719199, NCT00633529, [180]). While resiquimod, a TLR7/8 agonist, showed an 
immunomodulatory effect on melanoma patients (NCT00960752), another TLR9 agonist, tilsotolimod, was tested in combination with standard immune checkpoint inhibitors (ICIs) in the treatment of advanced melanoma patients, showing beneficial effects as compared with ICIs alone (NCT03445533).

CD40 belongs to the TNF receptor superfamily and is expressed by APCs, including macrophages. The CD40 ligand (CD40L) is mainly expressed by T cells. The CD40-CD40L interaction upregulates the expression of MHC molecules and the production of proinflammatory cytokines, such as IL-12, both prototypical markers of M1-like macrophages [181]. Several anti-CD40 agonistic antibodies and CD40 ligands have been designed. Selicrelumab (RO7009789) and sotigalimab (APX005M) monoclonal antibodies are currently under clinical trials in the treatment of different solid tumors (e.g., pancreatic cancer, melanoma, sarcomas, pediatric neurological cancer) [181,182].

Interestingly, unlikely other Fc receptor agonists, the antibody Fc domain with inhibitory Fc $\gamma$ RIIb is required for the anti-CD40 antibody because of its agonistic immunostimulatory activity. CP-870893, an IgG2 anti-CD40 antibody, was more effective in inducing immunostimulation [181]. CP-870893 showed anti-tumor activity in patients with different solid tumors (NCT00607048), as well as in pancreatic cancer and in mesothelioma patients [181]. Of note, ABBV-428 is a mesothelin-CD40 bispecific molecule currently studied in a phase 1 clinical trial in combination with nivolumab for the treatment of patients with advanced solid tumors (NCT02955251).

PI3Ks are involved in almost all types of intracellular signaling. The class $1 \mathrm{~b}$ PI3K $\gamma$ is the only isoform expressed in myeloid cells and can inhibit NF- $\kappa$ B activation and, eventually, the pro-inflammatory phenotype of macrophages. Moreover, $\mathrm{PI} 3 \mathrm{~K} \gamma$ signaling drives the L-arginine metabolism from iNOS enzymatic activity toward the ARG1-mediated degradation, a crucial pathway for immunosuppression [114]. Of relevance, low activity of PI3K $\gamma$ in head and neck lung cancer patients correlated with better prognosis and longer overall survival [114]. Eganelisib (IPI-549), a selective PI3K $\gamma$ inhibitor, is currently being tested in phase $1 \mathrm{~b}$ clinical trials in combination with different standard therapies (e.g., doxorubicin, paclitaxel, nivolumab, bevacizumab), in triple-negative breast, non-small cell lung, head and neck, urothelial cancers and melanoma [183].

Histone deacetylases (HDACs) are responsible for removing the acetyl groups on histones, a crucial process in epigenetic regulation of gene expression. Tucidinostat (chidamide) inhibits Class I HDAC1, HDAC2, HDAC3, as well as Class IIb HDAC10, and has been approved by Chinese and Japanese FDA to be tested in clinical trials for the treatment of urothelial and gynecological cancers (NCT04562311, NCT04192903, NCT04651127).

\section{Re-Activation of Phagocytosis}

Myeloid cells, including macrophages, express $\operatorname{SIRP} \alpha$. Since CD47 is upregulated in both solid and hematological tumors and such overexpression is correlated with poor patient survival or poor response to therapy, several CD47-SIRP $\alpha$ antagonists were developed and are currently active in clinical trials [184]. These include: magrolimab (Hu5F9-G4), TTI-621, CC-95251, CC-90002 and STI-6643. Magrolimab is still under evaluation for the treatment of ovarian, breast, head and neck carcinomas, osteosarcoma, neuroblastoma, as well as hematological malignancies (see Table 2) [185]. TTI-621 is a fully human recombinant protein that blocks the CD47-SIRP $\alpha$ axis and improves the killing of cancer cells [185]. TTI-621 promoted macrophage-mediated tumor killing in a wide array of solid and hematologic malignancies. Currently, TTI-621 is also being tested on hematological neoplasms, leiomyosarcoma and multiple solid tumors (NCT02663518, NCT02890368, NCT04996004).

\section{Macrophage Engineering}

As mentioned above, genetic engineering approaches aimed to express chimeric antigen T cell receptor (CAR) against cancer-specific antigens has been developed [186]. More recently, academic laboratories and companies are developing CAR-expressing macrophages to selectively target tumor antigens. Notably, Klichinsky et al. described an anti-HER2 CAR-macrophage (CAR-M, CT-0508), endowed with antigen-specific phago- 
cytic activity, significantly reduced metastatic tumor burden in humanized mouse cancer model [138]. Of relevance, based on impressive preclinical results, the US FDA recently approved a phase 1 clinical trial for the treatment of HER2 ${ }^{+}$cancers (NCT04660929) [187].

\subsection{Clinical Trials Targeting MDSCs}

Although the history of the identification and characterization of MDSCs is much more recent as compared to TAMs, the efforts made for their therapeutic targeting in cancer are increasingly providing promising results. Indeed, while the identity of MDSCs is rather challenging, a number of clinical trials are ongoing, pursuing strategies that reduce their frequency [188]. As MDSCs and TAMs are ontologically and functionally akin, several strategies for their targeting overlap. Indeed, some clinical trials are evaluating the effects of therapeutic agents on both TAM and MDSC populations (e.g., anti-CCR2 (NCT02345408), anti-CCR5 (NCT03184870), anti-CXCR4 (NCT04058145)). Table 3 describes the major ongoing clinical trials targeting MDSCs.

\subsubsection{Abrogating MDSCs Enrichment}

\section{Inhibition of MDSCs Recruitment}

As with TAMs, the inhibition of MDSC trafficking to the tumor site is a promising strategy. The CXCL8 (IL-8) chemokine through its binding to CXCR1 or CXCR2 receptors supports tumor progression, partially promoting neutrophils and PMN-MDSCs recruitment [33]. In pre-clinical models, CXCR2 inhibition showed reduced MDSC frequency, increased T-cell infiltration, decreased tumor progression, as well as improved response to anti-PD-1 treatment [189].

At present, several CXCR1/2 inhibitors have been tested. SX-682, reparixin, navarixin and AZD5069 are the most studied, in combination with canonical chemotherapies, as well as with ICIs, showing promising results in terms of both tolerability and clinical outcome $[190,191]$. Recently, an anti-CXCL8 antibody, HuMax-IL-8, was confirmed to be safe and tolerable in patients with early-stage solid cancers and is currently under investigation in a phase 1/2 clinical study, in combination with nivolumab; however, indications about MDSCs' frequency and responsiveness to therapy have not been provided yet (NCT03400332).

CXCL12 levels were associated with CXCR4 ${ }^{+}$MDSCs accumulation in patients with ovarian cancers [192]. Two CXCR4 inhibiting agents, plerixafor and motixafortide, are now under investigation for the treatment of head and neck and pancreatic carcinoma patients, in which the MDSCs will be monitored (NCT04058145, NCT03193190). Interestingly, VEGF is an indispensable stimulator of mobilization and expansion of MDSCs expressing the VEGF receptor 1 (VEGFR1) [193]. Several clinical studies with anti-VEGF/VEGFR therapies (bevacizumab) demonstrated inhibitory effects on MDSCs' accumulation, in association with the inhibition of angiogenesis. Indeed, bevacizumab-based therapy significantly reduced the proportion of PMN-MDSCs in the peripheral blood of NSCLC patients [194]. Another study on patients with colorectal cancer showed that the FOLFOX regimen plus bevacizumab decreased PMN-MDSCs' frequency, as well as providing a better clinical outcome [195].

\section{Depletion of MDSCS}

Low-dose chemotherapy has been shown to exert immunomodulatory effects by eliminating MDSCs and reducing their immunosuppressive capability [196]. Gemcitabine and fluorouracil (5-FU) are the two most studied cytotoxic agents for MDSCs depletion in cancer bearers [197]. Multiple studies on gemcitabine, fluorouracil, as well as capecitabine and cyclophosphamide, are under clinical evaluation or have already demonstrated efficacy in combination with immunotherapies (e.g., DC vaccine, ICIs), resulting in decreased MDSC numbers and benefiting the survival of cancer patients (see Table 3) [196,198]. However, other cytotoxic drugs such as cyclophosphamide can induce the opposite result, inducing MDSCs' infiltration and expansion [199]. 
Table 3. Summarized list of completed or active clinical trials targeting MDSCs.

\begin{tabular}{|c|c|c|c|c|c|}
\hline Strategy & Target & Drug Name & Combined Therapy & Disease & Clinical Trial \\
\hline \multirow{15}{*}{$\begin{array}{l}\text { Inhibition of recruitment, } \\
\text { mobilization, expansion }\end{array}$} & \multirow{6}{*}{ CXCR1/2-CXCL8 } & \multirow{3}{*}{ SX-682 } & Nivolumab & Metastatic Colorectal Cancer & NCT04599140 \\
\hline & & & Nivolumab & Pancreatic Cancer & NCT04477343 \\
\hline & & & Pembrolizumab & Metastatic Melanoma & NCT03161431 \\
\hline & & Navarixin & Pembrolizumab & Advanced Solid Cancer & NCT03473925 \\
\hline & & \multirow[b]{2}{*}{ Reparixin } & Paclitaxel & Metastatic Breast Cancer & NCT02370238 \\
\hline & & & Paclitaxel & HER2-neg Metastatic Breast Cancer & NCT02001974 \\
\hline & \multirow{4}{*}{ CXCR2 } & \multirow{4}{*}{ AZD5069 } & \multirow{4}{*}{$\begin{array}{l}\text { Enzalutamide } \\
\text { Nab-paclitaxel, Gemcitabine, } \\
\text { MEDI4736 } \\
\text { AZD9150, MEDI4736, } \\
\text { Tremelimumab }\end{array}$} & \multirow{4}{*}{$\begin{array}{l}\text { Metastatic Prostate Cancer } \\
\text { Metastatic Pancreatic Ductal } \\
\text { Carcinoma } \\
\text { Head and Neck Carcinoma }\end{array}$} & NCT03177187 \\
\hline & & & & & NCT02583477 \\
\hline & & & & & \\
\hline & & & & & NCT02499328 \\
\hline & \multirow[b]{2}{*}{ CXCR4 } & Plerixafor & Pembrolizumab & Head and Neck Cancer & NCT04058145 \\
\hline & & Motixafortide & Atezolizumab & $\begin{array}{l}\text { Metastatic Pancreatic } \\
\text { Adenocarcinoma }\end{array}$ & NCT03193190 \\
\hline & \multirow{3}{*}{ VEGF/VEGFR } & \multirow[t]{2}{*}{ Bevacizumab } & Pazopanib Hydrochloride & Renal Cell Cancer & NCT01684397 \\
\hline & & & Anakinra & Metastatic Colorectal Cancer & NCT02090101 \\
\hline & & Cabozantinib & Single agent & Prostate Cancer & NCT03964337 \\
\hline \multirow{10}{*}{ Depleting MDSCs } & \multirow{10}{*}{ Whole cell } & \multirow{4}{*}{ Gemcitabine } & Nivolumab & Non-small Cell Lung Cancer & NCT04331626 \\
\hline & & & Modified vaccine expressing p53 & Gynecological Cancers & NCT02275039 \\
\hline & & & DC vaccine & Breast Cancer & NCT02479230 \\
\hline & & & DC vaccine, imiquimod & Sarcomas & NCT01803152 \\
\hline & & \multirow{2}{*}{ Fluorouracil } & Avelumab, Cisplatin, Mitomycin & Bladder Cancer & NCT03617913 \\
\hline & & & Aldesleukin, Chemotherapies & Pancreatic Cancer & NCT02620865 \\
\hline & & \multirow[b]{2}{*}{ Capecitabine } & Avelumab & Colorectal Cancer & NCT03854799 \\
\hline & & & Cisplatin, Rituximab & $\begin{array}{l}\text { Head and Neck Squamous Cell } \\
\text { Cancer }\end{array}$ & NCT04361409 \\
\hline & & \multirow{2}{*}{ Cyclophosphamide } & iNKT cells, hrIL-2 & Hepatocellular Carcinoma & NCT04011033 \\
\hline & & & Pembrolizumab, Vit D, Aspirin & Gynecological Cancer & NCT03192059 \\
\hline
\end{tabular}


Table 3. Cont.

\begin{tabular}{|c|c|c|c|c|c|}
\hline Strategy & Target & Drug Name & Combined Therapy & Disease & Clinical Trial \\
\hline \multirow{10}{*}{$\begin{array}{l}\text { Promoting MDSC } \\
\text { differentiation }\end{array}$} & \multirow{4}{*}{ TLRs } & Poly ICLC & IMA 950 & CNS Tumor & NCT01920191 \\
\hline & & Imiquimod & DC vaccine & Glioblastoma & NCT01808820 \\
\hline & & Motolimod & Cetuximab, Nivolumab & $\begin{array}{l}\text { Head and Neck Squamous Cell } \\
\text { Cancer }\end{array}$ & NCT02124850 \\
\hline & & CpG & Nivolumab & Pancreatic Cancer & NCT04612530 \\
\hline & \multirow{4}{*}{ RAR/RXR } & \multirow{4}{*}{ ATRA } & Ipilimumab & Melanoma & NCT02403778 \\
\hline & & & Pembrolizumab & Melanoma & NCT03200847 \\
\hline & & & Vaccine, Cyclophosphamide & Lung Cancer & NCT00601796 \\
\hline & & & Paclitaxel, p53-DC vaccines & Small Cell Lung Cancer & NCT00617409 \\
\hline & \multirow{2}{*}{ STAT3 } & \multirow{2}{*}{ Danvatirsen } & Durvalumab & Pancreatic, Colorectal, Lung Cancer & NCT02983578 \\
\hline & & & Durvalumab & Non-Small Cell Lung Cancer & NCT03794544 \\
\hline \multirow{16}{*}{$\begin{array}{l}\text { Inhibiting } \\
\text { suppressive functions }\end{array}$} & \multirow{7}{*}{ TGF $\beta$} & ABBV-151 & Budigalimab & Advanced Solid Cancer & NCT03821935 \\
\hline & & Pirfenidone & Atezolizumab & $\begin{array}{l}\text { Advanced Non-Small Cell Lung } \\
\text { Cancer }\end{array}$ & NCT04467723 \\
\hline & & NIS793 & PDR001 & Advanced Solid Cancer & NCT02947165 \\
\hline & & \multirow{4}{*}{ Bintrafusp alfa } & Single agent & Advanced Solid Cancer & NCT02517398 \\
\hline & & & Single agent & Advanced Solid Cancer & NCT02699515 \\
\hline & & & Single agent & HPV-associated malignancies & NCT03427411 \\
\hline & & & Cheotherapy & Non-Small Cell Lung Cancer & NCT03840915 \\
\hline & \multirow{4}{*}{$\mathrm{COX} 2$} & Acetylsalicylic acid & Pembrolizumab, Clopidogrel & Head and Neck Cancer & NCT03245489 \\
\hline & & \multirow{3}{*}{ Celecoxib } & DC vaccine, cisplatin & Ovarian Cancer & NCT02432378 \\
\hline & & & Nivolumab, Ipilimumab & Colorectal Cancer & NCT03026140 \\
\hline & & & Glucoferon, Rintatolimod & Metastatic Breast Cancer & NCT03599453 \\
\hline & \multirow[b]{2}{*}{ PDE5 } & \multirow[b]{2}{*}{ Tadalafil } & Single agent & Head and Neck Cancer & NCT01697800 \\
\hline & & & Anti-Tumor Mucin-1 Vaccine & $\begin{array}{l}\text { Head and Neck Squamous Cell } \\
\text { Cancer }\end{array}$ & NCT02544880 \\
\hline & \multirow{3}{*}{ HDACs } & \multirow{3}{*}{ Entinostat } & Ipilimumab, Nivolumab & Breast Cancer & NCT02453620 \\
\hline & & & Nivolumab & Pancreatic Cancer & NCT03250273 \\
\hline & & & Azacitidine, Nivolumab & Non-Small Cell Lung Cancer & NCT01928576 \\
\hline
\end{tabular}


Table 3. Cont.

\begin{tabular}{|c|c|c|c|c|c|}
\hline Strategy & Target & Drug Name & Combined Therapy & Disease & Clinical Trial \\
\hline & & & Ipilimumab, Nivolumab & Melanoma & NCT02259231 \\
\hline & NRF2 & Omaveloxolone & Single Agent & NSC Lung Cancer, Melanoma & NCT02029729 \\
\hline \multirow{13}{*}{$\begin{array}{l}\text { Modulation } \\
\text { of MDSC } \\
\text { metabolism }\end{array}$} & \multirow{7}{*}{ CD39/CD73 } & TTX-030 & Pembrolizumab, Chemotherapies & Advanced Solid Cancer & NCT04306900 \\
\hline & & SRF617 & Chemotherapies, Pembrolizumab & Advanced Solid Cancer & NCT04336098 \\
\hline & & \multirow{5}{*}{ Oleclumab } & Durvalumab & Muscle Invasive Bladder Cancer & NCT03773666 \\
\hline & & & Durvalumab & Lung and Renal Cancer & NCT04262375 \\
\hline & & & Durvalumab & $\begin{array}{l}\text { Head and Neck, Lung, Pancreatic } \\
\text { Cancer }\end{array}$ & NCT04262388 \\
\hline & & & Paclitaxel, Carboplatin, MEDI4736 & Triple Negative Breast Cancer & NCT03616886 \\
\hline & & & Durvalumab & Sarcomas & NCT04668300 \\
\hline & \multirow{3}{*}{ IDO } & Indoximod & Docetaxel, Paclitaxel & Metastatic Breast Cancer & NCT01792050 \\
\hline & & Epacadostat & Pembrolizumab & Melanoma & NCT02752074 \\
\hline & & BMS-986205 & $\begin{array}{l}\text { Nivolumab, Radiation, } \\
\text { Temozolomide }\end{array}$ & Glioblastoma & NCT04047706 \\
\hline & \multirow{2}{*}{ ARG1 } & \multirow{2}{*}{ INCB001158 } & Retifanlimab & Advanced Solid Cancer & NCT03910530 \\
\hline & & & Chemotherapies & Advanced Solid Cancer & NCT03314935 \\
\hline & LXRs & RGX-104 & ICIs, Chemotherapies & Advanced Solid Cancer, Lymphoma & NCT02922764 \\
\hline
\end{tabular}




\subsubsection{Re-Education of MDSCs}

\section{Promoting MDSCs Maturation}

The immature phenotype of MDSCs represents another promising target to reduce their accumulation and to overcome their immunosuppressive functions. In this regard, polyinosinic-polycytidylic acid (Poly ICLC), a synthetic double-stranded RNA ligand for TLR3 used as an immunostimulatory adjuvant, showed effects in reducing MDSCs frequency and related immunosuppression [200]. Currently, Poly ICLC is being evaluated for the treatment of central nervous system (CNS) tumors, and for its effect on MDSCs and Tregs frequency. However, while safety, tolerability and clinical outcomes showed positive results, MDSCs' frequency and functions were not provided (NCT01920191) [201]. TLR7/8 agonists synergize with immunotherapeutic approaches to enhance antitumor efficacy, by preventing MDSCs suppressive functions [202,203]. In a phase 1 clinical trial (NCT02124850) in HNSCC patients, the TLR8 agonist motolimod in combination with cetuximab reduced the MDSCs' frequency, inducing pro-inflammatory monocytic differentiation in tumor tissues [204]. CpG motifs, agonists of TLR9, have antitumoral immune activity as therapeutic vaccine adjuvants [205]. In addition, a clinical study in pancreatic cancer patients is testing the combination of $\mathrm{CpG}$ with nivolumab for safety and efficacy, evaluating the effects elicited on MDSCs (NCT04612530).

ATRA is a derivative of vitamin A with agonist activity towards retinoid-activated transcriptional regulators (RARs and RXRs). ATRA induces the maturation of immature myeloid cells into fully differentiated and less immunosuppressive cells [206]. ATRA was approved by the FDA as a standard treatment for acute promyelocytic leukemia (APL), as it promotes terminal differentiation of immature myelocytic tumor cells [207], and consequently proposed for the differentiation of immature MDSCs into macrophages and DCs [208]. A clinical trial in renal cell carcinoma (RCC) demonstrated that ATRA treatment reduced total CD33 ${ }^{+}$MDSCs, and induced a stable disease in the majority of patients [209]. Another trial on metastatic melanoma patients tested ATRA in combination with standard ipilimumab therapy, proving a reduced number of circulating MDSCs as compared with ipilimumab therapy alone (NCT02403778) [210]. Furthermore, the combination of ATRA with a p53-transduced DC vaccine in SCLC patients showed a reduced number of total and M-MDSCs and improved the anti-cancer immune response. However, no clinical outcomes have been reported from this trial [153]. STAT3 activation is a key event regulating expansion and immunosuppressive functions of MDSCs, preventing their terminal differentiation [79]. Among others (see Table 3), a phase 1 trial (NCT01563302) revealed that systemic administration of danvartisen, an antisense oligonucleotide inhibitor of STAT3, reduced the levels of peripheral PMN-MDSCs in patients with diffuse large B-cell lymphoma (DLBCL) [211]. Moreover, a phase II clinical trial tested the AZD9150 STAT3 inhibitor in combination with ICIs in solid tumor patients (NCT02499328).

\section{Inhibition of MDSCs Immunosuppressive Functions}

TGF $\beta$ mediates several immunosuppressive activities during tumor development, including expansion and induction of immunosuppressive MDSCs [76]. Accordingly, several strategies targeting TGF $\beta$ are under clinical evaluation. These include TGF $\beta$ inhibitors (ABBV-151, pirfenidone) and blocking antibodies (NIS793, SAR439459) (Table 3). Interestingly, bintrafusp alpha (M7824), a bispecific fusion protein blocking both PD-L1 and TGF $\beta$, is under clinical evaluation for the treatment of different solid tumors, where the frequency of immunosuppressive MDSCs is being characterized (Table 3).

PGE2 is involved in inflammation, angiogenesis, tumor progression via MDSCs recruitment, ARG1 upregulation and regulation of PD-L1 expression on tumor-infiltrating MDSCs [212,213], promotion of CXCL12/CXCR4-mediated recruitment of MDSCs [192]. PGE2 is synthesized from arachidonic acid by cyclooxygenases (COXs). Celecoxib, a selective inhibitor of COX-2, has been of great interest as a treatment suppressing MDSC functions, alone and in combination with ICIs. Various clinical trials combining Celecoxib with standard therapies are currently ongoing, characterizing MDSC s' enrichment and func- 
tions [214]. However, COX inhibitors showed adverse effects as a result of pan-inhibition of prostanoid production; therefore, targeting the downstream receptors of PGE2 (e.g., prostaglandin E receptors/EPs) can be a more beneficial approach [215]. In a phase I clinical trial in patients with advanced solid tumors, an EP4 inhibitor significantly enhanced tumor infiltration of $\mathrm{CD}^{+}$and $\mathrm{CD}^{+} \mathrm{T}$ cells, while the levels of MDSCs in these patients were not reported (NCT02540291).

Phosphodiesterase 5 (PDE5) inhibitors, such as tadalafil, have been reported to downregulate the expression of ARG1, iNOS, and IL-4Ra in MDSCs [216]. Tadalafil treatment in metastatic melanoma and HNSCC patients proved to be safe and able to significantly reduce MDSCs accumulation, as well as ARG1 and iNOS activity [217,218]. Moreover, a phase I trial testing tadalafil and a telomerase vaccine (GV1001), alongside gemcitabine, is ongoing in patients with locally advanced pancreatic adenocarcinoma (NCT01342224).

As with TAMs, HDAC inhibitors induced a significant reduction in ARG1 and COX2 expression in MDSCs, impaired MDSC trafficking and promoted their differentiation towards a macrophage-like phenotype, improving the response to immunotherapeutic agents $[219,220]$. The class I HDAC inhibitor, entinostat, is currently under study in different clinical trials. While two clinical trials on breast and ovarian cancer (NCT02708680, NCT02915523) failed to improve the clinical response, other studies combining entinostat with ICIs are underway for the treatment of breast, pancreatic and non-small cell lung cancer (NSCLC) [221] (Table 3).

\section{Modulation of MDSCs Metabolism}

The ectonucleotidases CD39 and CD73 catalyze the conversion of ATP/ADP to adenosine, which play a pivotal role in immunosuppression. Significant expression of CD39/CD73 was detected on the surface of MDSCs in lung and colon cancer patients, and was significantly associated with the response to chemotherapy, and hence was suggested to promote angiogenic process [222]. Therefore, many strategies inhibiting CD39/CD73 have been explored in clinical trials, in combination with ICIs. Among these inhibitors, TTX-030, SRF617 and oleclumab (MEDI9447) are being tested in bladder, lung, renal, breast cancers (Table 3). Tryptophan catabolism via the activity of IDO enzyme is a generally accepted mediator of immunosuppression in tumors and IDO expression is positively correlated with disease stage in many human cancers [223]. IDO is highly expressed by tumor-infiltrating immune cells, such as MDSCs [224]. Although the inhibition of IDO with epacadostat in combination with pembrolizumab failed in improving melanoma patients outcome [225], other phase III studies on pembrolizumab plus epacadostat showed a higher response rate in different solid tumors, as compared to control groups (NCT03361865; NCT03374488; NCT03260894; NCT03358472). Moreover, other IDO inhibitors, such as indoximod, in combination with the prostate cancer vaccine sipuleucel-T showed a positive clinical response (NCT01560923). Other drugs which regulate MDSCs include ARG1 inhibitor (INCB001158) (Table 3) [226], metformin [227], LXRs agonist RGX-104 (NCT02922764), and vitamin D3 [228].

\section{Conclusions and Future Perspective}

Although specific immunity is rightly considered the effector arm of antitumor response, and numerous strategies have been devised to reinforce specific lymphocyte responses in cancer patients, it is increasingly evident that the expansion of myeloid populations induced by growing tumors dramatically interferes with specific antitumor immunity and with the efficacy of anticancer therapies. Furthermore, new antitumor strategies (e.g., CD47/SIRP $\alpha$ antagonists) are being defined, aimed at the reactivation of cytotoxic properties typical of innate immunity. Therefore, the future integration of strategies involving both innate and specific immunity seems no longer postponable, as well as on the basis of new knowledge that points to myeloid cells as a powerful protumoral immune checkpoint. The mechanisms that drive "emergency myelopoiesis" in cancer patients and the functional integration of the multistep events leading to the development of the suppressor phenotype of myeloid cells are therefore to be considered as essential biological traits of 
tumor progression. Future studies will therefore have to better understand the functional integration of the processes that contribute to establishing protumoral myeloid conditions, both at a systemic and intratumor level. This may lead to the optimization of strategies aimed at the functional misalignment of what appears to be an interconnected multistep process of protumoral reprogramming. This multitargeting approach will probably make tumors more attackable from a therapeutic point of view, restoring effective cooperation between innate and specific antitumor responses.

Achieving this goal will require the acquisition of new basic knowledge and its translation into new clinical studies evaluating the effects of drugs targeting the immunosuppressive myeloid compartment in combination with standard therapies and/or immunotherapies.

Author Contributions: Conceptualization, A.B., F.M.C. and A.S.; writing-original draft preparation, A.B., F.M.C., C.P., V.G. and A.S.; figure design, A.B., F.M.C. and V.G.; writing-review and editing, A.B. and F.M.C.; supervision, A.S. All authors have read and agreed to the published version of the manuscript.

Funding: This work was supported by the Associazione Italiana per la Ricerca sul Cancro (AIRC) IG numbers 19885; AIRC $5 \times 1000$ number 22757; Fondazione Cariplo 2016/0871, Ministero Università Ricerca (MIUR) (project N²017BA9LM5_001); Associazione “Augusto per la Vita", Novellara; Associazione "Medicine Rocks", Milano; Fondazione Umberto Veronesi (ID 1844503-CovIBD).

Conflicts of Interest: The authors declare no conflict of interest.

\section{References}

1. Sica, A.; Guarneri, V.; Gennari, A. Myelopoiesis, metabolism and therapy: A crucial crossroads in cancer progression. Cell Stress 2019, 3, 284-294. [CrossRef]

2. Chavakis, T.; Mitroulis, I.; Hajishengallis, G. Hematopoietic progenitor cells as integrative hubs for adaptation to and fine-tuning of inflammation. Nat. Immunol. 2019, 20, 802-811. [CrossRef]

3. Escamilla-Tilch, M.; Filio-Rodríguez, G.; García-Rocha, R.; Mancilla-Herrera, I.; Mitchison, N.A.; Ruiz-Pacheco, J.A.; SánchezGarcía, F.J.; Sandoval-Borrego, D.; Vázquez-Sánchez, E.A. The interplay between pathogen-associated and danger-associated molecular patterns: An inflammatory code in cancer. Immunol. Cell Biol. 2013, 91, 601-610. [CrossRef]

4. Janeway, C.A. Approaching the asymptote? Evolution and revolution in immunology. Cold Spring Harb. Symp. Quant. Biol. 1989, 54, 1-13. [CrossRef]

5. Strauss, L.; Guarneri, V.; Gennari, A.; Sica, A. Implications of metabolism-driven myeloid dysfunctions in cancer therapy. Cell. Mol. Immunol. 2021, 18, 829-841. [CrossRef]

6. Travelli, C.; Consonni, F.M.; Sangaletti, S.; Storto, M.; Morlacchi, S.; Grolla, A.A.; Galli, U.; Tron, G.C.; Portararo, P.; Rimassa, L.; et al. Nicotinamide phosphoribosyltransferase acts as a metabolic gate for mobilization of myeloid-derived suppressor cells. Cancer Res. 2019, 79, 1938-1951. [CrossRef]

7. Porta, C.; Consonni, F.M.; Morlacchi, S.; Sangaletti, S.; Bleve, A.; Totaro, M.G.; Larghi, P.; Rimoldi, M.; Tripodo, C.; Strauss, L.; et al. Tumor-derived prostaglandin E2 promotes p50 NF-kB-dependent differentiation of monocytic MDSCs. Cancer Res. 2020, 80, 2874-2888. [CrossRef]

8. Mantovani, A.; Marchesi, F.; Malesci, A.; Laghi, L.; Allavena, P. Tumour-associated macrophages as treatment targets in oncology. Nat. Rev. Clin. Oncol. 2017, 14, 399-416. [CrossRef]

9. Weiss, J.M. The promise and peril of targeting cell metabolism for cancer therapy. Cancer Immunol. Immunother. 2020, 69, 255-261. [CrossRef]

10. Iwasaki, H.; Akashi, K. Myeloid Lineage Commitment from the Hematopoietic Stem Cell. Immunity 2007, 26, 726-740. [CrossRef]

11. Trumpp, A.; Essers, M.; Wilson, A. Awakening dormant haematopoietic stem cells. Nat. Rev. Immunol. 2010, 10, 201-209. [CrossRef]

12. Gabrilovich, D.I.; Ostrand-Rosenberg, S.; Bronte, V. Coordinated regulation of myeloid cells by tumours. Nat. Rev. Immunol. 2012, 12, 253-268. [CrossRef]

13. Hedrick, C.C.; Malanchi, I. Neutrophils in cancer: Heterogeneous and multifaceted. Nat. Rev. Immunol. 2021. [CrossRef] [PubMed]

14. Hinshaw, D.C.; Shevde, L.A. The tumor microenvironment innately modulates cancer progression. Cancer Res. 2019, 79, 4557-4567. [CrossRef] [PubMed]

15. Lichterman, J.N.; Reddy, S.M. Mast cells: A new frontier for cancer immunotherapy. Cells 2021, 10, 1270. [CrossRef] [PubMed]

16. Manz, M.G.; Boettcher, S. Emergency granulopoiesis. Nat. Rev. Immunol. 2014, 14, 302-314. [CrossRef]

17. Pietras, E.M.; Mirantes-Barbeito, C.; Fong, S.; Loeffler, D.; Kovtonyuk, L.V.; Zhang, S.; Lakshminarasimhan, R.; Chin, C.P.; Techner, J.M.; Will, B.; et al. Chronic interleukin-1 exposure drives haematopoietic stem cells towards precocious myeloid differentiation at the expense of self-renewal. Nat. Cell Biol. 2016, 18, 607-618. [CrossRef] 
18. Montfort, A.; Colacios, C.; Levade, T.; Andrieu-Abadie, N.; Meyer, N.; Ségui, B. The TNF paradox in cancer progression and immunotherapy. Front. Immunol. 2019, 10, 1818. [CrossRef]

19. Zhao, X.; Rong, L.; Zhao, X.; Li, X.; Liu, X.; Deng, J.; Wu, H.; Xu, X.; Erben, U.; Wu, P.; et al. TNF signaling drives myeloid-derived suppressor cell accumulation. J. Clin. Investig. 2012, 122, 4094-4104. [CrossRef]

20. Condamine, T.; Mastio, J.; Gabrilovich, D.I. Transcriptional regulation of myeloid-derived suppressor cells. J. Leukoc. Biol. 2015, 98, 913-922. [CrossRef]

21. Hirai, H.; Zhang, P.; Dayaram, T.; Hetherington, C.J.; Mizuno, S.I.; Imanishi, J.; Akashi, K.; Tenen, D.G. C/EBP $\beta$ is required for “emergency" granulopoiesis. Nat. Immunol. 2006, 7, 732-739. [CrossRef] [PubMed]

22. Strauss, L.; Sangaletti, S.; Consonni, F.M.; Szebeni, G.; Morlacchi, S.; Totaro, M.G.; Porta, C.; Anselmo, A.; Tartari, S.; Doni, A.; et al. RORC1 Regulates Tumor-Promoting “Emergency" Granulo-Monocytopoiesis. Cancer Cell 2015, 28, 253-269. [CrossRef]

23. Consonni, F.M.; Bleve, A.; Totaro, M.G.; Storto, M.; Kunderfranco, P.; Termanini, A.; Pasqualini, F.; Ali, C.; Pandolfo, C.; Sgambelluri, F.; et al. Heme catabolism by tumor-associated macrophages controls metastasis formation. Nat. Immunol. 2021, 22, 595-606. [CrossRef] [PubMed]

24. Richter, R.; Forssmann, W.; Henschler, R. Current Developments in Mobilization of Hematopoietic Stem and Progenitor Cells and Their Interaction with Niches in Bone Marrow. Transfus. Med. Hemotherapy 2017, 44, 151-164. [CrossRef]

25. Sun, H.W.; Wu, W.C.; Chen, H.T.; Xu, Y.T.; Yang, Y.Y.; Chen, J.; Yu, X.J.; Wang, Z.; Shuang, Z.Y.; Zheng, L. Glutamine Deprivation Promotes the Generation and Mobilization of MDSCs by Enhancing Expression of G-CSF and GM-CSF. Front. Immunol. 2021, 11, 616367. [CrossRef] [PubMed]

26. Gomes, A.L.; Carvalho, T.; Serpa, J.; Torre, C.; Dias, S. Hypercholesterolemia promotes bone marrow cell mobilization by perturbing the SDF-1:CXCR4 axis. Blood 2010, 115, 3886-3894. [CrossRef] [PubMed]

27. Adamiak, M.; Poniewierska-Baran, A.; Borkowska, S.; Schneider, G.; Abdelbaset-Ismail, A.; Suszynska, M.; Abdel-Latif, A.; Kucia, M.; Ratajczak, J.; Ratajczak, M.Z. Evidence that a lipolytic enzyme-hematopoietic-specific phospholipase C- $\beta 2$-promotes mobilization of hematopoietic stem cells by decreasing their lipid raft-mediated bone marrow retention and increasing the promobilizing effects of granulocytes. Leukemia 2016, 30, 919-928. [CrossRef] [PubMed]

28. Brennan, F.H.; Jogia, T.; Gillespie, E.R.; Blomster, L.V.; Li, X.X.; Nowlan, B.; Williams, G.M.; Jacobson, E.; Osborne, G.W.; Meunier, F.A.; et al. Complement receptor C3aR1 controls neutrophil mobilization following spinal cord injury through physiological antagonism of CXCR2. JCI Insight 2019, 4, e98254. [CrossRef] [PubMed]

29. Qian, B.Z.; Li, J.; Zhang, H.; Kitamura, T.; Zhang, J.; Campion, L.R.; Kaiser, E.A.; Snyder, L.A.; Pollard, J.W. CCL2 recruits inflammatory monocytes to facilitate breast-tumour metastasis. Nature 2011, 475, 222-225. [CrossRef]

30. Jung, H.; Mithal, D.S.; Park, J.E.; Miller, R.J. Localized CCR2 activation in the bone marrow niche mobilizes monocytes by desensitizing CXCR4. PLoS ONE 2015, 10, e0128387. [CrossRef]

31. Mantovani, A.; Allavena, P.; Sozzani, S.; Vecchi, A.; Locati, M.; Sica, A. Chemokines in the recruitment and shaping of the leukocyte infiltrate of tumors. Semin. Cancer Biol. 2004, 14, 155-160. [CrossRef] [PubMed]

32. Korbecki, J.; Grochans, S.; Gutowska, I.; Barczak, K.; Baranowska-Bosiacka, I. Cc chemokines in a tumor: A review of pro-cancer and anti-cancer properties of receptors ccr5, ccr6, ccr7, ccr8, ccr9, and ccr10 ligands. Int. J. Mol. Sci. 2020, 21, 7619. [CrossRef]

33. Li, B.H.; Garstka, M.A.; Li, Z.F. Chemokines and their receptors promoting the recruitment of myeloid-derived suppressor cells into the tumor. Mol. Immunol. 2020, 117, 201-215. [CrossRef] [PubMed]

34. Engblom, C.; Pfirschke, C.; Pittet, M.J. The role of myeloid cells in cancer therapies. Nat. Rev. Cancer 2016, 16, 447-462. [CrossRef] [PubMed]

35. Bruni, D.; Angell, H.K.; Galon, J. The immune contexture and Immunoscore in cancer prognosis and therapeutic efficacy. Nat. Rev. Cancer 2020, 20, 662-680. [CrossRef] [PubMed]

36. Kiss, M.; Van Gassen, S.; Movahedi, K.; Saeys, Y.; Laoui, D. Myeloid cell heterogeneity in cancer: Not a single cell alike. Cell. Immunol. 2018, 330, 188-201. [CrossRef]

37. Geissmann, F.; Gordon, S.; Hume, D.A.; Mowat, A.M.; Randolph, G.J. Unravelling mononuclear phagocyte heterogeneity. Nat. Rev. Immunol. 2010, 10, 453-460. [CrossRef]

38. Casanova-Acebes, M.; Dalla, E.; Leader, A.M.; LeBerichel, J.; Nikolic, J.; Morales, B.M.; Brown, M.; Chang, C.; Troncoso, L.; Chen, S.T.; et al. Tissue-resident macrophages provide a pro-tumorigenic niche to early NSCLC cells. Nature 2021, 595, 578-584. [CrossRef]

39. Tirosh, I.; Izar, B.; Prakadan, S.M.; Wadsworth, M.H.; Treacy, D.; Trombetta, J.J.; Rotem, A.; Rodman, C.; Lian, C.; Murphy, G.; et al. Dissecting the multicellular ecosystem of metastatic melanoma by single-cell RNA-seq. Science 2016, 352, 189-196. [CrossRef]

40. Chevrier, S.; Levine, J.H.; Zanotelli, V.R.T.; Silina, K.; Schulz, D.; Bacac, M.; Ries, C.H.; Ailles, L.; Jewett, M.A.S.; Moch, H.; et al. An Immune Atlas of Clear Cell Renal Cell Carcinoma. Cell 2017, 169, 736-749.e18. [CrossRef]

41. Azizi, E.; Carr, A.J.; Plitas, G.; Cornish, A.E.; Konopacki, C.; Prabhakaran, S.; Nainys, J.; Wu, K.; Kiseliovas, V.; Setty, M.; et al. Single-Cell Map of Diverse Immune Phenotypes in the Breast Tumor Microenvironment. Cell 2018, 174, 1293-1308.e36. [CrossRef]

42. Donadon, M.; Torzilli, G.; Cortese, N.; Soldani, C.; Di Tommaso, L.; Franceschini, B.; Carriero, R.; Barbagallo, M.; Rigamonti, A.; Anselmo, A.; et al. Macrophage morphology correlates with single-cell diversity and prognosis in colorectal liver metastasis. J. Exp. Med. 2020, 217, e20191847. [CrossRef]

43. Zhang, L.; Li, Z.; Skrzypczynska, K.M.; Fang, Q.; Zhang, W.; O’Brien, S.A.; He, Y.; Wang, L.; Zhang, Q.; Kim, A.; et al. Single-Cell Analyses Inform Mechanisms of Myeloid-Targeted Therapies in Colon Cancer. Cell 2020, 181, 442-459.e29. [CrossRef] [PubMed] 
44. Lei, Y.; Tang, R.; Xu, J.; Wang, W.; Zhang, B.; Liu, J.; Yu, X.; Shi, S. Applications of single-cell sequencing in cancer research: Progress and perspectives. J. Hematol. Oncol. 2021, 14, 91. [CrossRef]

45. Maynard, A.; McCoach, C.E.; Rotow, J.K.; Harris, L.; Haderk, F.; Kerr, D.L.; Yu, E.A.; Schenk, E.L.; Tan, W.; Zee, A.; et al. Therapy-Induced Evolution of Human Lung Cancer Revealed by Single-Cell RNA Sequencing. Cell 2020, 182, 1232-1251.e22. [CrossRef] [PubMed]

46. Murray, P.J.; Allen, J.E.; Biswas, S.K.; Fisher, E.A.; Gilroy, D.W.; Goerdt, S.; Gordon, S.; Hamilton, J.A.; Ivashkiv, L.B.; Lawrence, T.; et al. Macrophage Activation and Polarization: Nomenclature and Experimental Guidelines. Immunity 2014, 41, 14-20. [CrossRef] [PubMed]

47. Yang, M.; McKay, D.; Pollard, J.W.; Lewis, C.E. Diverse functions of macrophages in different tumor microenvironments. Cancer Res. 2018, 78, 5492-5503. [CrossRef] [PubMed]

48. Fu, L.Q.; Du, W.L.; Cai, M.H.; Yao, J.Y.; Zhao, Y.Y.; Mou, X.Z. The roles of tumor-associated macrophages in tumor angiogenesis and metastasis. Cell. Immunol. 2020, 353, 104119. [CrossRef]

49. De Palma, M.; Biziato, D.; Petrova, T.V. Microenvironmental regulation of tumour angiogenesis. Nat. Rev. Cancer 2017, 17, 457-474. [CrossRef]

50. De Palma, M.; Naldini, L. Angiopoietin-2 TIEs up macrophages in tumor angiogenesis. Clin. Cancer Res. 2011, 17, 5226-5232. [CrossRef]

51. Kato, S.; Okamura, R.; Kumaki, Y.; Ikeda, S.; Nikanjam, M.; Eskander, R.; Goodman, A.; Lee, S.; Glenn, S.T.; Dressman, D.; et al. Expression of TIM3/VISTA checkpoints and the CD68 macrophage-associated marker correlates with anti-PD1/PDL1 resistance: Implications of immunogram heterogeneity. Oncoimmunology 2020, 9, 1708065. [CrossRef]

52. Ruffell, B.; Affara, N.I.; Coussens, L.M. Differential macrophage programming in the tumor microenvironment. Trends Immunol. 2012, 33, 119-126. [CrossRef]

53. Bosurgi, L.; Cao, Y.G.; Cabeza-Cabrerizo, M.; Tucci, A.; Hughes, L.D.; Kong, Y.; Weinstein, J.S.; Licona-Limon, P.; Schmid, E.T.; Pelorosso, F; et al. Macrophage function in tissue repair and remodeling requires IL-4 or IL-13 with apoptotic cells. Science 2017, 356, 1072-1076. [CrossRef] [PubMed]

54. Pastò, A.; Consonni, F.M.; Sica, A. Influence of innate immunity on cancer cell stemness. Int. J. Mol. Sci. 2020, 21, 3352. [CrossRef]

55. Quail, D.F.; Joyce, J.A. Microenvironmental regulation of tumor progression and metastasis. Nat. Med. 2013, $19,1423-1437$. [CrossRef] [PubMed]

56. Forssell, J.; Öberg, Å.; Henriksson, M.L.; Stenling, R.; Jung, A.; Palmqvist, R. High macrophage infiltration along the tumor front correlates with improved survival in colon cancer. Clin. Cancer Res. 2007, 3, 1472-1479. [CrossRef] [PubMed]

57. Wagner, J.; Rapsomaniki, M.A.; Chevrier, S.; Anzeneder, T.; Langwieder, C.; Dykgers, A.; Rees, M.; Ramaswamy, A.; Muenst, S.; Soysal, S.D.; et al. A Single-Cell Atlas of the Tumor and Immune Ecosystem of Human Breast Cancer. Cell 2019, 177, 1330-1345.e18. [CrossRef]

58. Sica, A.; Mantovani, A. Macrophage plasticity and polarization: In vivo veritas. J. Clin. Investig. 2012, 122, 787-795. [CrossRef] [PubMed]

59. Zhang, Q.; He, Y.; Luo, N.; Patel, S.J.; Han, Y.; Gao, R.; Modak, M.; Carotta, S.; Haslinger, C.; Kind, D.; et al. Landscape and Dynamics of Single Immune Cells in Hepatocellular Carcinoma. Cell 2019, 179, 829-845.e20. [CrossRef]

60. Cassetta, L.; Fragkogianni, S.; Sims, A.H.; Swierczak, A.; Forrester, L.M.; Zhang, H.; Soong, D.Y.H.; Cotechini, T.; Anur, P.; Lin, E.Y.; et al. Human Tumor-Associated Macrophage and Monocyte Transcriptional Landscapes Reveal Cancer-Specific Reprogramming, Biomarkers, and Therapeutic Targets. Cancer Cell 2019, 35, 588-602.e10. [CrossRef] [PubMed]

61. Kwak, T.; Wang, F.; Deng, H.; Condamine, T.; Kumar, V.; Perego, M.; Kossenkov, A.; Montaner, L.J.; Xu, X.; Xu, W.; et al. Distinct Populations of Immune-Suppressive Macrophages Differentiate from Monocytic Myeloid-Derived Suppressor Cells in Cancer. Cell Rep. 2020, 33, 108571. [CrossRef] [PubMed]

62. Veglia, F.; Sanseviero, E.; Gabrilovich, D.I. Myeloid-derived suppressor cells in the era of increasing myeloid cell diversity. Nat. Rev. Immunol. 2021, 21, 485-498. [CrossRef] [PubMed]

63. Franklin, R.A.; Liao, W.; Sarkar, A.; Kim, M.V.; Bivona, M.R.; Liu, K.; Pamer, E.G.; Li, M.O. The cellular and molecular origin of tumor-associated macrophages. Science 2014, 344, 921-925. [CrossRef] [PubMed]

64. Bowman, R.L.; Klemm, F.; Akkari, L.; Pyonteck, S.M.; Sevenich, L.; Quail, D.F.; Dhara, S.; Simpson, K.; Gardner, E.E.; IacobuzioDonahue, C.A.; et al. Macrophage Ontogeny Underlies Differences in Tumor-Specific Education in Brain Malignancies. Cell Rep. 2016, 17, 2445-2459. [CrossRef]

65. Zhu, Y.; Herndon, J.M.; Sojka, D.K.; Kim, K.W.; Knolhoff, B.L.; Zuo, C.; Cullinan, D.R.; Luo, J.; Bearden, A.R.; Lavine, K.J.; et al. Tissue-Resident Macrophages in Pancreatic Ductal Adenocarcinoma Originate from Embryonic Hematopoiesis and Promote Tumor Progression. Immunity 2017, 47, 323-338.e6. [CrossRef]

66. Loyher, P.L.; Hamon, P.; Laviron, M.; Meghraoui-Kheddar, A.; Goncalves, E.; Deng, Z.; Torstensson, S.; Bercovici, N.; De Chanville, C.B.; Combadière, B.; et al. Macrophages of distinct origins contribute to tumor development in the lung. J. Exp. Med. 2018, 215, 2536-2553. [CrossRef] [PubMed]

67. Etzerodt, A.; Moulin, M.; Doktor, T.K.; Delfini, M.; Mossadegh-Keller, N.; Bajenoff, M.; Sieweke, M.H.; Moestrup, S.K.; AuphanAnezin, N.; Lawrence, T. Tissue-resident macrophages in omentum promote metastatic spread of ovarian cancer. J. Exp. Med. 2020, 217, e20191869. [CrossRef] 
68. Grover, A.; Sanseviero, E.; Timosenko, E.; Gabrilovich, D.I. Myeloid-Derived Suppressor Cells: A Propitious Road to Clinic. Cancer Discov. 2021, 11, 2693-2706. [CrossRef]

69. Bronte, V.; Brandau, S.; Chen, S.H.; Colombo, M.P.; Frey, A.B.; Greten, T.F.; Mandruzzato, S.; Murray, P.J.; Ochoa, A.; OstrandRosenberg, S.; et al. Recommendations for myeloid-derived suppressor cell nomenclature and characterization standards. Nat. Commun. 2016, 7, 12150. [CrossRef]

70. Hegde, S.; Leader, A.M.; Merad, M. MDSC: Markers, development, states, and unaddressed complexity. Immunity 2021, 54, 875-884. [CrossRef]

71. Koh, J.; Kim, Y.; Lee, K.Y.; Hur, J.Y.; Kim, M.S.; Kim, B.; Cho, H.J.; Lee, Y.C.; Bae, Y.H.; Ku, B.M.; et al. MDSC subtypes and CD39 expression on CD8+ T cells predict the efficacy of anti-PD-1 immunotherapy in patients with advanced NSCLC. Eur. J. Immunol. 2020, 50, 1810-1819. [CrossRef] [PubMed]

72. Joseph, E.L.M.; Laheurte, C.; Jary, M.; Boullerot, L.; Asgarov, K.; Gravelin, E.; Bouard, A.; Rangan, L.; Dosset, M.; Borg, C.; et al. Immunoregulation and clinical implications of ANGPT2/Tie2+ m-MDSC signature in non-small cell lung cancer. Cancer Immunol. Res. 2020, 8, 268-279. [CrossRef] [PubMed]

73. Sade-Feldman, M.; Kanterman, J.; Klieger, Y.; Ish-Shalom, E.; Olga, M.; Saragovi, A.; Shtainberg, H.; Lotem, M.; Baniyash, M. Clinical significance of circulating CD33+ CD11bHLA-DR myeloid cells in patients with stage IV melanoma treated with ipilimumab. Clin. Cancer Res. 2016, 22, 5661-5672. [CrossRef]

74. Porta, C.; Marino, A.; Consonni, F.M.; Bleve, A.; Mola, S.; Storto, M.; Riboldi, E.; Sica, A. Metabolic influence on the differentiation of suppressive myeloid cells in cancer. Carcinogenesis 2018, 39, 1095-1104. [CrossRef]

75. Condamine, T.; Ramachandran, I.; Youn, J.-I.; Gabrilovich, D.I. Regulation of Tumor Metastasis by Myeloid-Derived Suppressor Cells. Annu. Rev. Med. 2015, 66, 97-110. [CrossRef] [PubMed]

76. Consonni, F.M.; Porta, C.; Marino, A.; Pandolfo, C.; Mola, S.; Bleve, A.; Sica, A. Myeloid-derived suppressor cells: Ductile targets in disease. Front. Immunol. 2019, 10, 949. [CrossRef]

77. Yang, Y.; Li, C.; Liu, T.; Dai, X.; Bazhin, A.V. Myeloid-Derived Suppressor Cells in Tumors: From Mechanisms to Antigen Specificity and Microenvironmental Regulation. Front. Immunol. 2020, 11, 1371. [CrossRef] [PubMed]

78. Lu, C.; Redd, P.S.; Lee, J.R.; Savage, N.; Liu, K. The expression profiles and regulation of PD-L1 in tumor-induced myeloid-derived suppressor cells. Oncoimmunology 2016, 5, e1247135. [CrossRef]

79. Trovato, R.; Fiore, A.; Sartori, S.; Canè, S.; Giugno, R.; Cascione, L.; Paiella, S.; Salvia, R.; De Sanctis, F.; Poffe, O.; et al Immunosuppression by monocytic myeloid-derived suppressor cells in patients with pancreatic ductal carcinoma is orchestrated by STAT3. J. Immunother. Cancer 2019, 7, 255. [CrossRef] [PubMed]

80. Ugel, S.; De Sanctis, F.; Mandruzzato, S.; Bronte, V. Tumor-induced myeloid deviation: When myeloid-derived suppressor cells meet tumor-Associated macrophages. J. Clin. Investig. 2015, 125, 3365-3376. [CrossRef]

81. Marvel, D.; Gabrilovich, D.I. Myeloid-derived suppressor cells in the tumor microenvironment: Expect the unexpected. J. Clin. Investig. 2015, 125, 3356-3364. [CrossRef] [PubMed]

82. Condamine, T.; Dominguez, G.A.; Youn, J.I.; Kossenkov, A.V.; Mony, S.; Alicea-Torres, K.; Tcyganov, E.; Hashimoto, A.; Nefedova, Y.; Lin, C.; et al. Lectin-type oxidized LDL receptor-1 distinguishes population of human polymorphonuclear myeloid-derived suppressor cells in cancer patients. Sci. Immunol. 2016, 1, aaf8943. [CrossRef]

83. Alshetaiwi, H.; Pervolarakis, N.; McIntyre, L.L.; Ma, D.; Nguyen, Q.; Rath, J.A.; Nee, K.; Hernandez, G.; Evans, K.; Torosian, L.; et al. Defining the emergence of myeloid-derived suppressor cells in breast cancer using single-cell transcriptomics. Sci. Immunol. 2020, 5. [CrossRef]

84. Song, Q.; Hawkins, G.A.; Wudel, L.; Chou, P.C.; Forbes, E.; Pullikuth, A.K.; Liu, L.; Jin, G.; Craddock, L.; Topaloglu, U.; et al. Dissecting intratumoral myeloid cell plasticity by single cell RNA-seq. Cancer Med. 2019, 8, 3072-3085. [CrossRef]

85. Masucci, M.T.; Minopoli, M.; Carriero, M.V. Tumor Associated Neutrophils. Their Role in Tumorigenesis, Metastasis, Prognosis and Therapy. Front. Oncol. 2019, 9, 1146. [CrossRef] [PubMed]

86. Jaillon, S.; Ponzetta, A.; Di Mitri, D.; Santoni, A.; Bonecchi, R.; Mantovani, A. Neutrophil diversity and plasticity in tumour progression and therapy. Nat. Rev. Cancer 2020, 20, 485-503. [CrossRef] [PubMed]

87. Coffelt, S.B.; Wellenstein, M.D.; De Visser, K.E. Neutrophils in cancer: Neutral no more. Nat. Rev. Cancer 2016, 16, 431-446. [CrossRef]

88. Zhu, Y.P.; Eggert, T.; Araujo, D.J.; Vijayanand, P.; Ottensmeier, C.H.; Hedrick, C.C. CyTOF mass cytometry reveals phenotypically distinct human blood neutrophil populations differentially correlated with melanoma stage. J. Immunother. Cancer 2020, 8, e000473. [CrossRef]

89. Engblom, C.; Pfirschke, C.; Zilionis, R.; Da Silva Martins, J.; Bos, S.A.; Courties, G.; Rickelt, S.; Severe, N.; Baryawno, N.; Faget, J.; et al. Osteoblasts remotely supply lung tumors with cancer-promoting SiglecFhigh neutrophils. Science 2017, 358, eaal5081. [CrossRef]

90. Zilionis, R.; Engblom, C.; Pfirschke, C.; Savova, V.; Zemmour, D.; Saatcioglu, H.D.; Krishnan, I.; Maroni, G.; Meyerovitz, C.V.; Kerwin, C.M.; et al. Single-Cell Transcriptomics of Human and Mouse Lung Cancers Reveals Conserved Myeloid Populations across Individuals and Species. Immunity 2019, 50, 1317-1334.e10. [CrossRef] [PubMed]

91. Lavin, Y.; Kobayashi, S.; Leader, A.; Amir, E.a.D.; Elefant, N.; Bigenwald, C.; Remark, R.; Sweeney, R.; Becker, C.D.; Levine, J.H.; et al. Innate Immune Landscape in Early Lung Adenocarcinoma by Paired Single-Cell Analyses. Cell 2017, 169, 750-765.e17. [CrossRef] [PubMed] 
92. Fridlender, Z.G.; Sun, J.; Kim, S.; Kapoor, V.; Cheng, G.; Ling, L.; Worthen, G.S.; Albelda, S.M. Polarization of Tumor-Associated Neutrophil Phenotype by TGF- $\beta$ : “N1” versus “N2” TAN. Cancer Cell 2009, 16, 183-194. [CrossRef] [PubMed]

93. Reis, E.S.; Mastellos, D.C.; Ricklin, D.; Mantovani, A.; Lambris, J.D. Complement in cancer: Untangling an intricate relationship. Nat. Rev. Immunol. 2018, 18, 5-18. [CrossRef]

94. Singhal, S.; Bhojnagarwala, P.S.; O’Brien, S.; Moon, E.K.; Garfall, A.L.; Rao, A.S.; Quatromoni, J.G.; Stephen, T.L.; Litzky, L.; Deshpande, C.; et al. Origin and Role of a Subset of Tumor-Associated Neutrophils with Antigen-Presenting Cell Features in Early Stage Human Lung Cancer. Cancer Cell 2016, 30, 120-135. [CrossRef]

95. Wculek, S.K.; Malanchi, I. Neutrophils support lung colonization of metastasis-initiating breast cancer cells. Nature 2015, 528, 413-417. [CrossRef]

96. He, G.; Zhang, H.; Zhou, J.; Wang, B.; Chen, Y.; Kong, Y.; Xie, X.; Wang, X.; Fei, R.; Wei, L.; et al. Peritumoural neutrophils negatively regulate adaptive immunity via the PD-L1/PD-1 signalling pathway in hepatocellular carcinoma. J. Exp. Clin. Cancer Res. 2015, 34, 141. [CrossRef] [PubMed]

97. Feldmeyer, N.; Wabnitz, G.; Leicht, S.; Luckner-minden, C.; Schiller, M.; Franz, T.; Conradi, R.; Kropf, P.; Müller, I.; Ho, A.D.; et al. Arginine deficiency leads to impaired cofilin dephosphorylation in activated human T lymphocytes. Int. Immunol. 2012, 24, 303-313. [CrossRef]

98. Park, J.; Wysocki, R.W.; Amoozgar, Z.; Maiorino, L.; Fein, M.R.; Jorns, J.; Schott, A.F.; Kinugasa-Katayama, Y.; Lee, Y.; Won, N.H.; et al. Cancer cells induce metastasis-supporting neutrophil extracellular DNA traps. Sci. Transl. Med. 2016, 8, 361ra138. [CrossRef]

99. Lee, W.J.; Ko, S.Y.; Mohamed, M.S.; Kenny, H.A.; Lengyel, E.; Naora, H. Neutrophils facilitate ovarian cancer premetastatic niche formation in the omentum. J. Exp. Med. 2019, 216, 176-194. [CrossRef]

100. Tohme, S.; Yazdani, H.O.; Al-Khafaji, A.B.; Chidi, A.P.; Loughran, P.; Mowen, K.; Wang, Y.; Simmons, R.L.; Huang, H.; Tsung, A. Neutrophil extracellular traps promote the development and progression of liver metastases after surgical stress. Cancer Res. 2016, 76, 1367-1380. [CrossRef]

101. Albrengues, J.; Shields, M.A.; Ng, D.; Park, C.G.; Ambrico, A.; Poindexter, M.E.; Upadhyay, P.; Uyeminami, D.L.; Pommier, A.; Küttner, V.; et al. Neutrophil extracellular traps produced during inflammation awaken dormant cancer cells in mice. Science 2018, 361, eaao4227. [CrossRef]

102. Teijeira, Á.; Garasa, S.; Gato, M.; Alfaro, C.; Migueliz, I.; Cirella, A.; de Andrea, C.; Ochoa, M.C.; Otano, I.; Etxeberria, I.; et al. CXCR1 and CXCR2 Chemokine Receptor Agonists Produced by Tumors Induce Neutrophil Extracellular Traps that Interfere with Immune Cytotoxicity. Immunity 2020, 52, 856-871.e8. [CrossRef] [PubMed]

103. Ries, C.H.; Cannarile, M.A.; Hoves, S.; Benz, J.; Wartha, K.; Runza, V.; Rey-Giraud, F.; Pradel, L.P.; Feuerhake, F.; Klaman, I.; et al. Targeting tumor-associated macrophages with anti-CSF-1R antibody reveals a strategy for cancer therapy. Cancer Cell 2014, 25, 846-859. [CrossRef]

104. Pyonteck, S.M.; Akkari, L.; Schuhmacher, A.J.; Bowman, R.L.; Sevenich, L.; Quail, D.F.; Olson, O.C.; Quick, M.L.; Huse, J.T.; Teijeiro, V.; et al. CSF-1R inhibition alters macrophage polarization and blocks glioma progression. Nat. Med. 2013, 19, 1264-1272. [CrossRef]

105. Lesokhin, A.M.; Hohl, T.M.; Kitano, S.; Cortez, C.; Hirschhorn-Cymerman, D.; Avogadri, F.; Rizzuto, G.A.; Lazarus, J.J.; Pamer, E.G.; Houghton, A.N.; et al. Monocytic CCR2 + myeloid-derived suppressor cells promote immune escape by limiting activated CD8 T-cell infiltration into the tumor microenvironment. Cancer Res. 2012, 72, 876-886. [CrossRef] [PubMed]

106. Bonapace, L.; Coissieux, M.M.; Wyckoff, J.; Mertz, K.D.; Varga, Z.; Junt, T.; Bentires-Alj, M. Cessation of CCL2 inhibition accelerates breast cancer metastasis by promoting angiogenesis. Nature 2014, 515, 130-133. [CrossRef]

107. Litmanovich, A.; Khazim, K.; Cohen, I. The Role of Interleukin-1 in the Pathogenesis of Cancer and its Potential as a Therapeutic Target in Clinical Practice. Oncol. Ther. 2018, 6, 109-127. [CrossRef]

108. Germano, G.; Frapolli, R.; Belgiovine, C.; Anselmo, A.; Pesce, S.; Liguori, M.; Erba, E.; Uboldi, S.; Zucchetti, M.; Pasqualini, F.; et al. Role of Macrophage Targeting in the Antitumor Activity of Trabectedin. Cancer Cell 2013, 23, 249-262. [CrossRef] [PubMed]

109. Etzerodt, A.; Tsalkitzi, K.; Maniecki, M.; Damsky, W.; Delfini, M.; Baudoin, E.; Moulin, M.; Bosenberg, M.; Graversen, J.H.; Auphan-Anezin, N.; et al. Specific targeting of CD163+ TAMs mobilizes inflammatory monocytes and promotes T cell-mediated tumor regression. J. Exp. Med. 2019, 216, 2394-2411. [CrossRef] [PubMed]

110. Mullins, S.R.; Vasilakos, J.P.; Deschler, K.; Grigsby, I.; Gillis, P.; John, J.; Elder, M.J.; Swales, J.; Timosenko, E.; Cooper, Z.; et al. Intratumoral immunotherapy with TLR7/8 agonist MEDI9197 modulates the tumor microenvironment leading to enhanced activity when combined with other immunotherapies. J. Immunother. Cancer 2019, 7, 244. [CrossRef]

111. Beatty, G.L.; Chiorean, E.G.; Fishman, M.P.; Saboury, B.; Teitelbaum, U.R.; Sun, W.; Huhn, R.D.; Song, W.; Li, D.; Sharp, L.L.; et al. CD40 agonists alter tumor stroma and show efficacy against pancreatic carcinoma in mice and humans. Science 2011, 331, 1612-1616. [CrossRef] [PubMed]

112. Wiehagen, K.R.; Girgis, N.M.; Yamada, D.H.; Smith, A.A.; Chan, S.R.; Grewal, I.S.; Quigley, M.; Verona, R.I. Combination of CD40 agonism and CSF-1R blockade reconditions tumor-associated macrophages and drives potent antitumor immunity. Cancer Immunol. Res. 2017, 5, 1109-1121. [CrossRef]

113. Schmid, M.C.; Avraamides, C.J.; Dippold, H.C.; Franco, I.; Foubert, P.; Ellies, L.G.; Acevedo, L.M.; Manglicmot, J.R.E.; Song, X.; Wrasidlo, W.; et al. Receptor tyrosine kinases and TLR/IL1Rs Unexpectedly activate myeloid cell PI3K $\gamma$, A single convergent point promoting tumor inflammation and progression. Cancer Cell 2011, 19, 715-727. [CrossRef] [PubMed] 
114. Kaneda, M.M.; Messer, K.S.; Ralainirina, N.; Li, H.; Leem, C.J.; Gorjestani, S.; Woo, G.; Nguyen, A.V.; Figueiredo, C.C.; Foubert, P.; et al. PI3K $\gamma 3$ is a molecular switch that controls immune suppression. Nature 2016, 539, 437-442. [CrossRef] [PubMed]

115. De Henau, O.; Rausch, M.; Winkler, D.; Campesato, L.F.; Liu, C.; Cymerman, D.H.; Budhu, S.; Ghosh, A.; Pink, M.; Tchaicha, J.; et al. Overcoming resistance to checkpoint blockade therapy by targeting PI3K $\gamma$ in myeloid cells. Nature 2016, 539, $443-447$. [CrossRef] [PubMed]

116. Medler, T.R.; Murugan, D.; Horton, W.; Kumar, S.; Cotechini, T.; Forsyth, A.M.; Leyshock, P.; Leitenberger, J.J.; Kulesz-Martin, M.; Margolin, A.A.; et al. Complement C5a Fosters Squamous Carcinogenesis and Limits T Cell Response to Chemotherapy. Cancer Cell 2018, 34, 561-578.e6. [CrossRef] [PubMed]

117. Zha, H.; Han, X.; Zhu, Y.; Yang, F.; Li, Y.; Li, Q.; Guo, B.; Zhu, B. Blocking C5aR signaling promotes the anti-tumor efficacy of PD-1/PD-L1 blockade. Oncoimmunology 2017, 6, e1349587. [CrossRef] [PubMed]

118. Magrini, E.; Di Marco, S.; Mapelli, S.N.; Perucchini, C.; Pasqualini, F.; Donato, A.; Guevara Lopez, M.d.l.L.; Carriero, R.; Ponzetta, A.; Colombo, P.; et al. Complement activation promoted by the lectin pathway mediates C3aR-dependent sarcoma progression and immunosuppression. Nat. Cancer 2021, 2, 218-232. [CrossRef]

119. O'Neill, L.A.J.; Kishton, R.J.; Rathmell, J. A guide to immunometabolism for immunologists. Nat. Rev. Immunol. 2016, 16, 553-565. [CrossRef]

120. Bleve, A.; Durante, B.; Sica, A.; Consonni, F.M. Lipid metabolism and cancer immunotherapy: Immunosuppressive myeloid cells at the crossroad. Int. J. Mol. Sci. 2020, 21, 5845. [CrossRef]

121. Semba, H.; Takeda, N.; Isagawa, T.; Sugiura, Y.; Honda, K.; Wake, M.; Miyazawa, H.; Yamaguchi, Y.; Miura, M.; Jenkins, D.M.R.; et al. HIF-1 $\alpha$-PDK1 axis-induced active glycolysis plays an essential role in macrophage migratory capacity. Nat. Commun. 2016, 7, 11635. [CrossRef]

122. Arts, R.J.W.; Plantinga, T.S.; Tuit, S.; Ulas, T.; Heinhuis, B.; Tesselaar, M.; Sloot, Y.; Adema, G.J.; Joosten, L.A.B.; Smit, J.W.A.; et al. Transcriptional and metabolic reprogramming induce an inflammatory phenotype in non-medullary thyroid carcinoma-induced macrophages. Oncoimmunology 2016, 5, e1229725. [CrossRef] [PubMed]

123. Liu, P.S.; Wang, H.; Li, X.; Chao, T.; Teav, T.; Christen, S.; DI Conza, G.; Cheng, W.C.; Chou, C.H.; Vavakova, M.; et al. $\alpha-$ ketoglutarate orchestrates macrophage activation through metabolic and epigenetic reprogramming. Nat. Immunol. 2017, 18, 985-994. [CrossRef] [PubMed]

124. Palmieri, E.M.; Menga, A.; Martín-Pérez, R.; Quinto, A.; Riera-Domingo, C.; De Tullio, G.; Hooper, D.C.; Lamers, W.H.; Ghesquière, B.; McVicar, D.W.; et al. Pharmacologic or Genetic Targeting of Glutamine Synthetase Skews Macrophages toward an M1-like Phenotype and Inhibits Tumor Metastasis. Cell Rep. 2017, 20, 1654-1666. [CrossRef] [PubMed]

125. Hogg, S.J.; Beavis, P.A.; Dawson, M.A.; Johnstone, R.W. Targeting the epigenetic regulation of antitumour immunity. Nat. Rev. Drug Discov. 2020, 19, 776-800. [CrossRef]

126. Guerriero, J.L.; Sotayo, A.; Ponichtera, H.E.; Castrillon, J.A.; Pourzia, A.L.; Schad, S.; Johnson, S.F.; Carrasco, R.D.; Lazo, S.; Bronson, R.T.; et al. Class IIa HDAC inhibition reduces breast tumours and metastases through anti-tumour macrophages. Nature 2017, 543, 428-432. [CrossRef]

127. Mola, S.; Pinton, G.; Erreni, M.; Corazzari, M.; Andrea, M.D.; Grolla, A.A.; Martini, V.; Moro, L.; Porta, C. Inhibition of the histone methyltransferase ezh2 enhances protumor monocyte recruitment in human mesothelioma spheroids. Int. J. Mol. Sci. 2021, 22, 4391. [CrossRef]

128. Hamaidia, M.; Gazon, H.; Hoyos, C.; Hoffmann, G.B.; Louis, R.; Duysinx, B.; Willems, L. Inhibition of EZH2 methyltransferase decreases immunoediting of mesothelioma cells by autologous macrophages through a PD-1-dependent mechanism. JCI Insight 2019, 4, e128474. [CrossRef]

129. Morel, K.L.; Sheahan, A.V.; Burkhart, D.L.; Baca, S.C.; Boufaied, N.; Liu, Y.; Qiu, X.; Cañadas, I.; Roehle, K.; Heckler, M.; et al. EZH2 inhibition activates a dsRNA-STING-interferon stress axis that potentiates response to PD-1 checkpoint blockade in prostate cancer. Nat. Cancer 2021, 2, 444-456. [CrossRef]

130. Feng, M.; Jiang, W.; Kim, B.Y.S.; Zhang, C.C.; Fu, Y.X.; Weissman, I.L. Phagocytosis checkpoints as new targets for cancer immunotherapy. Nat. Rev. Cancer 2019, 19, 568-586. [CrossRef]

131. Willingham, S.B.; Volkmer, J.P.; Gentles, A.J.; Sahoo, D.; Dalerba, P.; Mitra, S.S.; Wang, J.; Contreras-Trujillo, H.; Martin, R.; Cohen, J.D.; et al. The CD47-signal regulatory protein alpha (SIRPa) interaction is a therapeutic target for human solid tumors. Proc. Natl. Acad. Sci. USA 2012, 109, 6662-6667. [CrossRef] [PubMed]

132. Advani, R.; Flinn, I.; Popplewell, L.; Forero, A.; Bartlett, N.L.; Ghosh, N.; Kline, J.; Roschewski, M.; LaCasce, A.; Collins, G.P.; et al. CD47 Blockade by Hu5F9-G4 and Rituximab in Non-Hodgkin's Lymphoma. New Engl. J. Med. 2018, 379, 1711-1721. [CrossRef]

133. Gordon, S.R.; Maute, R.L.; Dulken, B.W.; Hutter, G.; George, B.M.; McCracken, M.N.; Gupta, R.; Tsai, J.M.; Sinha, R.; Corey, D.; et al. PD-1 expression by tumour-associated macrophages inhibits phagocytosis and tumour immunity. Nature 2017, 545, 495-499. [CrossRef] [PubMed]

134. Strauss, L.; Mahmoud, M.A.A.; Weaver, J.D.; Tijaro-Ovalle, N.M.; Christofides, A.; Wang, Q.; Pal, R.; Yuan, M.; Asara, J.; Patsoukis, N.; et al. Targeted deletion of PD-1 in myeloid cells induces antitumor immunity. Sci. Immunol. 2020, 5. [CrossRef]

135. Liu, X.; Liu, L.; Ren, Z.; Yang, K.; Xu, H.; Luan, Y.; Fu, K.; Guo, J.; Peng, H.; Zhu, M.; et al. Dual Targeting of Innate and Adaptive Checkpoints on Tumor Cells Limits Immune Evasion. Cell Rep. 2018, 24, 2101-2111. [CrossRef] 
136. Weiskopf, K.; Jahchan, N.S.; Schnorr, P.J.; Cristea, S.; Ring, A.M.; Maute, R.L.; Volkmer, A.K.; Volkmer, J.P.; Liu, J.; Lim, J.S.; et al. CD47-blocking immunotherapies stimulate macrophage-mediated destruction of small-cell lung cancer. J. Clin. Investig. 2016, 126, 2610-2620. [CrossRef] [PubMed]

137. Leijonhufvud, C.; Reger, R.; Segerberg, F.; Theorell, J.; Schlums, H.; Bryceson, Y.T.; Childs, R.W.; Carlsten, M. LIR-1 educates expanded human NK cells and defines a unique antitumor NK cell subset with potent antibody-dependent cellular cytotoxicity. Clin. Transl. Immunol. 2021, 10, e1346. [CrossRef] [PubMed]

138. Klichinsky, M.; Ruella, M.; Shestova, O.; Lu, X.M.; Best, A.; Zeeman, M.; Schmierer, M.; Gabrusiewicz, K.; Anderson, N.R.; Petty, N.E.; et al. Human chimeric antigen receptor macrophages for cancer immunotherapy. Nat. Biotechnol. 2020, 38, 947-953. [CrossRef] [PubMed]

139. Liang, H.; Deng, L.; Hou, Y.; Meng, X.; Huang, X.; Rao, E.; Zheng, W.; Mauceri, H.; Mack, M.; Xu, M.; et al. Host STING-dependent MDSC mobilization drives extrinsic radiation resistance. Nat. Commun. 2017, 8, 1736. [CrossRef] [PubMed]

140. Karin, N.; Razon, H. The role of CCR5 in directing the mobilization and biological function of CD11b+Gr1+Ly6Clow polymorphonuclear myeloid cells in cancer. Cancer Immunol. Immunother. 2018, 67, 1949-1953. [CrossRef] [PubMed]

141. Blattner, C.; Fleming, V.; Weber, R.; Himmelhan, B.; Altevogt, P.; Gebhardt, C.; Schulze, T.J.; Razon, H.; Hawila, E.; Wildbaum, G.; et al. CCR5+ myeloid-derived suppressor cells are enriched and activated in melanoma lesions. Cancer Res. 2018, 78, 157-167. [CrossRef] [PubMed]

142. Greene, S.; Robbins, Y.; Mydlarz, W.K.; Huynh, A.P.; Schmitt, N.C.; Friedman, J.; Horn, L.A.; Palena, C.; Schlom, J.; Maeda, D.Y.; et al. Inhibition of MDSC trafficking with SX-682, a CXCR1/2 inhibitor, enhances NK-cell immunotherapy in head and neck cancer models. Clin. Cancer Res. 2020, 26, 1420-1431. [CrossRef]

143. Wang, D.; Sun, H.; Wei, J.; Cen, B.; DuBois, R.N. CXCL1 is critical for premetastatic niche formation and metastasis in colorectal cancer. Cancer Res. 2017, 77, 3655-3665. [CrossRef] [PubMed]

144. Lin, S.; Wang, J.; Wang, L.; Wen, J.; Guo, Y.; Qiao, W.; Zhou, J.; Xu, G.; Zhi, F. Phosphodiesterase-5 inhibition suppresses colonic inflammation-induced tumorigenesis via blocking the recruitment of MDSC. Am. J. Cancer Res. 2017, 7, 41-52.

145. Fleming, V.; Hu, X.; Weber, R.; Nagibin, V.; Groth, C.; Altevogt, P.; Utikal, J.; Umansky, V. Targeting myeloid-derived suppressor cells to bypass tumor-induced immunosuppression. Front. Immunol. 2018, 9, 398. [CrossRef] [PubMed]

146. Condamine, T.; Kumar, V.; Ramachandran, I.R.; Youn, J.I.; Celis, E.; Finnberg, N.; El-Deiry, W.S.; Winograd, R.; Vonderheide, R.H.; English, N.R.; et al. ER stress regulates myeloid-derived suppressor cell fate through TRAIL-R-mediated apoptosis. J. Clin. Investig. 2014, 124, 2626-2639. [CrossRef] [PubMed]

147. Tavazoie, M.F.; Pollack, I.; Tanqueco, R.; Ostendorf, B.N.; Reis, B.S.; Gonsalves, F.C.; Kurth, I.; Andreu-Agullo, C.; Derbyshire, M.L.; Posada, J.; et al. LXR/ApoE Activation Restricts Innate Immune Suppression in Cancer. Cell 2018, 172, 825-840.e18. [CrossRef] [PubMed]

148. Zelenay, S.; Van Der Veen, A.G.; Böttcher, J.P.; Snelgrove, K.J.; Rogers, N.; Acton, S.E.; Chakravarty, P.; Girotti, M.R.; Marais, R.; Quezada, S.A.; et al. Cyclooxygenase-Dependent Tumor Growth through Evasion of Immunity. Cell 2015, 162, 1257-1270. [CrossRef]

149. Rodriguez, P.C.; Hernandez, C.P.; Quiceno, D.; Dubinett, S.M.; Zabaleta, J.; Ochoa, J.B.; Gilbert, J.; Ochoa, A.C. Arginase I in myeloid suppressor cells is induced by COX-2 in lung carcinoma. J. Exp. Med. 2005, 202, 931-939. [CrossRef] [PubMed]

150. Condamine, T.; Gabrilovich, D.I. Molecular mechanisms regulating myeloid-derived suppressor cell differentiation and function. Trends Immunol. 2011, 32, 19-25. [CrossRef]

151. Veglia, F.; Tyurin, V.A.; Blasi, M.; De Leo, A.; Kossenkov, A.V.; Donthireddy, L.; To, T.K.J.; Schug, Z.; Basu, S.; Wang, F.; et al. Fatty acid transport protein 2 reprograms neutrophils in cancer. Nature 2019, 569, 73-78. [CrossRef]

152. Kusmartsev, S.; Cheng, F.; Yu, B.; Nefedova, Y.; Sotomayor, E.; Lush, R.; Gabrilovich, D. All-trans-retinoic acid eliminates immature myeloid cells from tumor-bearing mice and improves the effect of vaccination. Cancer Res. 2003, 63, 4441-4449. [PubMed]

153. Iclozan, C.; Antonia, S.; Chiappori, A.; Chen, D.T.; Gabrilovich, D. Therapeutic regulation of myeloid-derived suppressor cells and immune response to cancer vaccine in patients with extensive stage small cell lung cancer. Cancer Immunol. Immunother. 2013, 62, 909-918. [CrossRef]

154. Bauer, R.; Udonta, F.; Wroblewski, M.; Ben-Batalla, I.; Santos, I.M.; Taverna, F.; Kuhlencord, M.; Gensch, V.; Päsler, S.; Vinckier, S.; et al. Blockade of myeloid-derived suppressor cell expansion with all-trans retinoic acid increases the efficacy of antiangiogenic therapy. Cancer Res. 2018, 78, 3220-3232. [CrossRef] [PubMed]

155. Liu, Z.; Xie, Y.; Xiong, Y.; Liu, S.; Qiu, C.; Zhu, Z.; Mao, H.; Yu, M.; Wang, X. TLR 7/8 agonist reverses oxaliplatin resistance in colorectal cancer via directing the myeloid-derived suppressor cells to tumoricidal M1-macrophages. Cancer Lett. 2020, 469, 173-185. [CrossRef]

156. Panni, R.Z.; Sanford, D.E.; Belt, B.A.; Mitchem, J.B.; Worley, L.A.; Goetz, B.D.; Mukherjee, P.; Wang-Gillam, A.; Link, D.C.; Denardo, D.G.; et al. Tumor-induced STAT3 activation in monocytic myeloid-derived suppressor cells enhances stemness and mesenchymal properties in human pancreatic cancer. Cancer Immunol. Immunother. 2014, 63, 513-528. [CrossRef]

157. Kortylewski, M.; Moreira, D. Myeloid cells as a target for oligonucleotide therapeutics: Turning obstacles into opportunities. Cancer Immunol. Immunother. 2017, 66, 979-988. [CrossRef]

158. Al-Khami, A.A.; Zheng, L.; Del Valle, L.; Hossain, F.; Wyczechowska, D.; Zabaleta, J.; Sanchez, M.D.; Dean, M.J.; Rodriguez, P.C.; Ochoa, A.C. Exogenous lipid uptake induces metabolic and functional reprogramming of tumor-associated myeloid-derived suppressor cells. Oncoimmunology 2017, 6, e1344804. [CrossRef] 
159. Huang, S.; Wang, Z.; Zhou, J.; Huang, J.; Zhou, L.; Luo, J.; Wan, Y.Y.; Long, H.; Zhu, B. EZH2 inhibitor GSK126 suppresses antitumor immunity by driving production of myeloid-derived suppressor cells. Cancer Res. 2019, 79, 2009-2020. [CrossRef]

160. Orillion, A.; Hashimoto, A.; Damayanti, N.; Shen, L.; Adelaiye-Ogala, R.; Arisa, S.; Chintala, S.; Ordentlich, P.; Kao, C.; Elzey, B.; et al. Entinostat neutralizes myeloid-derived suppressor cells and enhances the antitumor effect of PD-1 inhibition in murine models of lung and renal cell carcinoma. Clin. Cancer Res. 2017, 23, 5187-5201. [CrossRef] [PubMed]

161. Hegde, P.S.; Chen, D.S. Top 10 Challenges in Cancer Immunotherapy. Immunity 2020, 52, 17-35. [CrossRef]

162. Mantovani, A.; Marchesi, F.; Jaillon, S.; Garlanda, C.; Allavena, P. Tumor-associated myeloid cells: Diversity and therapeutic targeting. Cell. Mol. Immunol. 2021, 18, 566-578. [CrossRef]

163. Edin, S.; Wikberg, M.L.; Oldenborg, P.A.; Palmqvist, R. Macrophages: Good guys in colorectal cancer. Oncoimmunology 2013, 2, e23038. [CrossRef] [PubMed]

164. El-Arabey, A.A.; Denizli, M.; Kanlikilicer, P.; Bayraktar, R.; Ivan, C.; Rashed, M.; Kabil, N.; Ozpolat, B.; Calin, G.A.; Salama, S.A.; et al. GATA3 as a master regulator for interactions of tumor-associated macrophages with high-grade serous ovarian carcinoma. Cell. Signal. 2020, 68, 109539. [CrossRef] [PubMed]

165. Cannarile, M.A.; Weisser, M.; Jacob, W.; Jegg, A.M.; Ries, C.H.; Rüttinger, D. Colony-stimulating factor 1 receptor (CSF1R) inhibitors in cancer therapy. J. Immunother. Cancer 2017, 5, 53. [CrossRef]

166. Lewis, J.H.; Gelderblom, H.; van de Sande, M.; Stacchiotti, S.; Healey, J.H.; Tap, W.D.; Wagner, A.J.; Pousa, A.L.; Druta, M.; Lin, C.C.; et al. Pexidartinib Long-Term Hepatic Safety Profile in Patients with Tenosynovial Giant Cell Tumors. Oncologist 2021, 26, e863-e873. [CrossRef] [PubMed]

167. Benner, B.; Good, L.; Quiroga, D.; Schultz, T.E.; Kassem, M.; Carson, W.E.; Cherian, M.A.; Sardesai, S.; Wesolowski, R. Pexidartinib, a novel small molecule csf-1r inhibitor in use for tenosynovial giant cell tumor: A systematic review of pre-clinical and clinical development. Drug Des. Devel. Ther. 2020, 14, 1693-1704. [CrossRef]

168. Kuemmel, S.; Campone, M.; Loirat, D.; López López, R.; Beck, J.T.; De Laurentiis, M.; Im, S.-A.; Kim, S.-B.; Kwong, A.; Steger, G.G.; et al. A Randomized Phase II Study of Anti-CSF-1 Monoclonal Antibody Lacnotuzumab (MCS110) Combined with Gemcitabine and Carboplatin in Advanced Triple Negative Breast Cancer. Clin. Cancer Res. 2021, 28, 106-115. [CrossRef]

169. Fei, L.; Ren, X.; Yu, H.; Zhan, Y. Targeting the CCL2/CCR2 Axis in Cancer Immunotherapy: One Stone, Three Birds? Front. Immunol. 2021, 12, 771210. [CrossRef] [PubMed]

170. Pienta, K.J.; Machiels, J.P.; Schrijvers, D.; Alekseev, B.; Shkolnik, M.; Crabb, S.J.; Li, S.; Seetharam, S.; Puchalski, T.A.; Takimoto, C.; et al. Phase 2 study of carlumab (CNTO 888), a human monoclonal antibody against CC-chemokine ligand 2 (CCL2), in metastatic castration-resistant prostate cancer. Investig. New Drugs 2013, 31, 760-768. [CrossRef]

171. Nywening, T.M.; Wang-Gillam, A.; Sanford, D.E.; Belt, B.A.; Panni, R.Z.; Cusworth, B.M.; Toriola, A.T.; Nieman, R.K.; Worley, L.A.; Yano, M.; et al. Targeting tumour-associated macrophages with CCR2 inhibition in combination with FOLFIRINOX in patients with borderline resectable and locally advanced pancreatic cancer: A single-centre, open-label, dose-finding, non-randomised, phase $1 \mathrm{~b}$ trial. Lancet Oncol. 2016, 17, 651-662. [CrossRef]

172. Aldinucci, D.; Borghese, C.; Casagrande, N. The ccl5/ccr5 axis in cancer progression. Cancers 2020, 12, 1765. [CrossRef]

173. Scala, S. Molecular pathways: Targeting the CXCR4-CXCL12 Axis-Untapped potential in the tumor microenvironment. Clin. Cancer Res. 2015, 21, 4278-4285. [CrossRef]

174. Argyle, D.; Kitamura, T. Targeting macrophage-recruiting chemokines as a novel therapeutic strategy to prevent the progression of solid tumors. Front. Immunol. 2018, 9, 2629. [CrossRef]

175. Yusen, W.; Xia, W.; Shengjun, Y.; Shaohui, Z.; Hongzhen, Z. The expression and significance of tumor associated macrophages and CXCR4 in non-small cell lung cancer. J. BUON Off. J. Balk. Union Oncol. 2018, 23, 398-402.

176. Ji, N.; Mukherjee, N.; Morales, E.E.; Tomasini, M.E.; Hurez, V.; Curiel, T.J.; Abate, G.; Hoft, D.F.; Zhao, X.R.; Gelfond, J.; et al. Percutaneous BCG enhances innate effector antitumor cytotoxicity during treatment of bladder cancer: A translational clinical trial. Oncoimmunology 2019, 8, e1614857. [CrossRef]

177. Adams, S.; Kozhaya, L.; Martiniuk, F.; Meng, T.C.; Chiriboga, L.; Liebes, L.; Hochman, T.; Shuman, N.; Axelrod, D.; Speyer, J.; et al. Topical TLR7 agonist imiquimod can induce immune-mediated rejection of skin metastases in patients with breast cancer. Clin. Cancer Res. 2012, 18, 6748-6757. [CrossRef]

178. Chi, H.; Li, C.; Zhao, F.S.; Zhang, L.; Ng, T.B.; Jin, G.; Sha, O. Anti-tumor activity of Toll-like receptor 7 agonists. Front. Pharmacol. 2017, 8, 304. [CrossRef] [PubMed]

179. Ferris, R.L.; Saba, N.F.; Gitlitz, B.J.; Haddad, R.; Sukari, A.; Neupane, P.; Morris, J.C.; Misiukiewicz, K.; Bauman, J.E.; Fenton, M.; et al. Effect of adding motolimod to standard combination chemotherapy and cetuximab treatment of patients with squamous cell carcinoma of the head and neck the ACTIVE8 randomized clinical trial. JAMA Oncol. 2018, 4, 1583-1588. [CrossRef]

180. Smith, D.A.; Conkling, P.; Richards, D.A.; Nemunaitis, J.J.; Boyd, T.E.; Mita, A.C.; De La Bourdonnaye, G.; Wages, D.; Bexon, A.S Antitumor activity and safety of combination therapy with the Toll-like receptor 9 agonist IMO-2055, erlotinib, and bevacizumab in advanced or metastatic non-small cell lung cancer patients who have progressed following chemotherapy. Cancer Immunol. Immunother. 2014, 63, 787-796. [CrossRef] [PubMed]

181. Vonderheide, R.H. CD40 Agonist Antibodies in Cancer Immunotherapy. Annu. Rev. Med. 2020, 71, 47-58. [CrossRef]

182. O'Hara, M.H.; O’Reilly, E.M.; Varadhachary, G.; Wolff, R.A.; Wainberg, Z.A.; Ko, A.H.; Fisher, G.; Rahma, O.; Lyman, J.P.; Cabanski, C.R.; et al. CD40 agonistic monoclonal antibody APX005M (sotigalimab) and chemotherapy, with or without nivolumab, for the 
treatment of metastatic pancreatic adenocarcinoma: An open-label, multicentre, phase 1b study. Lancet Oncol. 2021, 22, 118-131. [CrossRef]

183. Zhu, J.; Li, K.; Yu, L.; Chen, Y.; Cai, Y.; Jin, J.; Hou, T. Targeting phosphatidylinositol 3-kinase gamma (PI3K $\gamma$ ): Discovery and development of its selective inhibitors. Med. Res. Rev. 2021, 41, 1599-1621. [CrossRef]

184. Logtenberg, M.E.W.; Scheeren, F.A.; Schumacher, T.N. The CD47-SIRP $\alpha$ Immune Checkpoint. Immunity 2020, 52, 742-752. [CrossRef] [PubMed]

185. Chao, M.P.; Takimoto, C.H.; Feng, D.D.; McKenna, K.; Gip, P.; Liu, J.; Volkmer, J.P.; Weissman, I.L.; Majeti, R. Therapeutic Targeting of the Macrophage Immune Checkpoint CD47 in Myeloid Malignancies. Front. Oncol. 2020, 9, 1380. [CrossRef]

186. Feins, S.; Kong, W.; Williams, E.F.; Milone, M.C.; Fraietta, J.A. An introduction to chimeric antigen receptor (CAR) T-cell immunotherapy for human cancer. Am. J. Hematol. 2020, 94, S3-S9. [CrossRef]

187. Carisma Therapeutics. Carisma Drives CAR-M Engineered Macrophage Cancer Therapy Forward. Available online: https: / / www.nature.com/articles/d43747-020-01096-y (accessed on 28 November 2021).

188. Ostrand-Rosenberg, S.; Fenselau, C. Myeloid-Derived Suppressor Cells: Immune-Suppressive Cells That Impair Antitumor Immunity and Are Sculpted by Their Environment. J. Immunol. 2018, 200, 422-431. [CrossRef]

189. Sun, L.; Clavijo, P.E.; Robbins, Y.; Patel, P.; Friedman, J.; Greene, S.; Das, R.; Silvin, C.; Van Waes, C.; Horn, L.A.; et al. Inhibiting myeloid-derived suppressor cell trafficking enhances T cell immunotherapy. JCI Insight 2019, 4, e126853. [CrossRef]

190. Elliott, L.A.; Doherty, G.A.; Sheahan, K.; Ryan, E.J. Human tumor-infiltrating myeloid cells: Phenotypic and functional diversity. Front. Immunol. 2017, 8, 86. [CrossRef]

191. Alfaro, C.; Sanmamed, M.F.; Rodríguez-Ruiz, M.E.; Teijeira, Á.; Oñate, C.; González, Á.; Ponz, M.; Schalper, K.A.; Pérez-Gracia, J.L.; Melero, I. Interleukin-8 in cancer pathogenesis, treatment and follow-up. Cancer Treat. Rev. 2017, 60, 24-31. [CrossRef] [PubMed]

192. Obermajer, N.; Muthuswamy, R.; Odunsi, K.; Edwards, R.P.; Kalinski, P. PGE 2-induced CXCL 12 production and CXCR4 expression controls the accumulation of human MDSCs in ovarian cancer environment. Cancer Res. 2011, 71, 7463-7470. [CrossRef]

193. Rivera, L.B.; Bergers, G. Intertwined regulation of angiogenesis and immunity by myeloid cells. Trends Immunol. 2015, 36, 240-249. [CrossRef]

194. Koinis, F.; Vetsika, E.K.; Aggouraki, D.; Skalidaki, E.; Koutoulaki, A.; Gkioulmpasani, M.; Georgoulias, V.; Kotsakis, A. Effect of first-line treatment on myeloid-derived suppressor cells' subpopulations in the peripheral blood of patients with non-small cell lung cancer. J. Thorac. Oncol. 2016, 11, 1263-1272. [CrossRef]

195. Limagne, E.; Euvrard, R.; Thibaudin, M.; Rébé, C.; Derangère, V.; Chevriaux, A.; Boidot, R.; Végran, F.; Bonnefoy, N.; Vincent, J.; et al. Accumulation of MDSC and Th17 cells in patients with metastatic colorectal cancer predicts the efficacy of a FOLFOXbevacizumab drug treatment regimen. Cancer Res. 2016, 76, 5241-5252. [CrossRef]

196. Zitvogel, L.; Apetoh, L.; Ghiringhelli, F.; Kroemer, G. Immunological aspects of cancer chemotherapy. Nat. Rev. Immunol. 2008, 8 , 59-73. [CrossRef]

197. Eriksson, E.; Wenthe, J.; Irenaeus, S.; Loskog, A.; Ullenhag, G. Gemcitabine reduces MDSCs, tregs and TGF $\beta-1$ while restoring the teff/treg ratio in patients with pancreatic cancer. J. Transl. Med. 2016, 14, 282. [CrossRef] [PubMed]

198. Peereboom, D.M.; Alban, T.J.; Grabowski, M.M.; Alvarado, A.G.; Otvos, B.; Bayik, D.; Roversi, G.; McGraw, M.; Huang, P.; Mohammadi, A.M.; et al. Metronomic capecitabine as an immune modulator in glioblastoma patients reduces myeloid-derived suppressor cells. JCI Insight 2019, 4, e130748. [CrossRef]

199. Takeuchi, S.; Baghdadi, M.; Tsuchikawa, T.; Wada, H.; Nakamura, T.; Abe, H.; Nakanishi, S.; Usui, Y.; Higuchi, K.; Takahashi, M.; et al. Chemotherapy-derived inflammatory responses accelerate the formation of immunosuppressive myeloid cells in the tissue microenvironment of human pancreatic cancer. Cancer Res. 2015, 75, 2629-2640. [CrossRef] [PubMed]

200. Forghani, P.; Waller, E.K. Poly (I: C) modulates the immunosuppressive activity of myeloid-derived suppressor cells in a murine model of breast cancer. Breast Cancer Res. Treat. 2015, 153, 21-30. [CrossRef] [PubMed]

201. Migliorini, D.; Dutoit, V.; Allard, M.; Grandjean Hallez, N.; Marinari, E.; Widmer, V.; Philippin, G.; Corlazzoli, F.; Gustave, R.; Kreutzfeldt, M.; et al. Phase I/II trial testing safety and immunogenicity of the multipeptide IMA950/poly-ICLC vaccine in newly diagnosed adult malignant astrocytoma patients. Neuro. Oncol. 2019, 21, 923-933. [CrossRef] [PubMed]

202. Lee, M.; Park, C.S.; Lee, Y.R.; Im, S.A.; Song, S.; Lee, C.K. Resiquimod, a TLR7/8 agonist, promotes differentiation of myeloidderived suppressor cells into macrophages and dendritic cells. Arch. Pharm. Res. 2014, 37, 1234-1240. [CrossRef]

203. Chow, L.Q.M.; Morishima, C.; Eaton, K.D.; Baik, C.S.; Goulart, B.H.; Anderson, L.N.; Manjarrez, K.L.; Dietsch, G.N.; Bryan, J.K.; Hershberg, R.M.; et al. Phase Ib trial of the Toll-like receptor 8 agonist, motolimod (VTX-2337), combined with cetuximab in patients with recurrent or metastatic SCCHN. Clin. Cancer Res. 2017, 23, 2442-2450. [CrossRef]

204. Shayan, G.; Kansy, B.A.; Gibson, S.P.; Srivastava, R.M.; Bryan, J.K.; Bauman, J.E.; Ohr, J.; Kim, S.; Duvvuri, U.; Clump, D.A.; et al. Phase $\mathrm{Ib}$ study of immune biomarker modulation with neoadjuvant cetuximab and TLR8 stimulation in head and neck cancer to overcome suppressive myeloid signals. Clin. Cancer Res. 2018, 24, 62-72. [CrossRef] [PubMed]

205. Vollmer, J.; Krieg, A.M. Immunotherapeutic applications of CpG oligodeoxynucleotide TLR9 agonists. Adv. Drug Deliv. Rev. 2009, 61, 195-204. [CrossRef] [PubMed]

206. Ni, X.; Hu, G.; Cai, X. The success and the challenge of all-trans retinoic acid in the treatment of cancer. Crit. Rev. Food Sci. Nutr. 2019, 59, S71-S80. [CrossRef] [PubMed] 
207. Lo-Coco, F.; Avvisati, G.; Vignetti, M.; Thiede, C.; Orlando, S.M.; Iacobelli, S.; Ferrara, F.; Fazi, P.; Cicconi, L.; Di Bona, E.; et al. Retinoic Acid and Arsenic Trioxide for Acute Promyelocytic Leukemia. New Engl. J. Med. 2013, 369, 111-121. [CrossRef] [PubMed]

208. Nefedova, Y.; Fishman, M.; Sherman, S.; Wang, X.; Beg, A.A.; Gabrilovich, D.I. Mechanism of all-trans retinoic acid effect on tumor-associated myeloid-derived suppressor cells. Cancer Res. 2007, 67, 11021-11028. [CrossRef] [PubMed]

209. Mirza, N.; Fishman, M.; Fricke, I.; Dunn, M.; Neuger, A.M.; Frost, T.J.; Lush, R.M.; Antonia, S.; Gabrilovich, D.I. All-trans-retinoic acid improves differentiation of myeloid cells and immune response in cancer patients. Cancer Res. 2006, 66, 9299-9307. [CrossRef] [PubMed]

210. Tobin, R.P.; Jordan, K.R.; Robinson, W.A.; Davis, D.; Borges, V.F.; Gonzalez, R.; Lewis, K.D.; McCarter, M.D. Targeting myeloidderived suppressor cells using all-trans retinoic acid in melanoma patients treated with Ipilimumab. Int. Immunopharmacol. 2018, 63, 282-291. [CrossRef]

211. Reilley, M.J.; McCoon, P.; Cook, C.; Lyne, P.; Kurzrock, R.; Kim, Y.; Woessner, R.; Younes, A.; Nemunaitis, J.; Fowler, N.; et al. STAT3 antisense oligonucleotide AZD9150 in a subset of patients with heavily pretreated lymphoma: Results of a phase $1 \mathrm{~b}$ trial. J. Immunother. Cancer 2018, 6, 119. [CrossRef]

212. Eruslanov, E.; Daurkin, I.; Ortiz, J.; Vieweg, J.; Kusmartsev, S. Pivotal Advance: Tumor-mediated induction of myeloid-derived suppressor cells and M2-polarized macrophages by altering intracellular PGE 2 catabolism in myeloid cells. J. Leukoc. Biol. 2010, 88, 839-848. [CrossRef] [PubMed]

213. Prima, V.; Kaliberova, L.N.; Kaliberov, S.; Curiel, D.T.; Kusmartsev, S. COX2/mPGES1/PGE2 pathway regulates PD-L1 expression in tumor-associated macrophages and myeloid-derived suppressor cells. Proc. Natl. Acad. Sci. USA 2017, 114, 1117-1122. [CrossRef]

214. Veltman, J.D.; Lambers, M.E.H.; van Nimwegen, M.; Hendriks, R.W.; Hoogsteden, H.C.; Aerts, J.G.J.V.; Hegmans, J.P.J.J. COX-2 inhibition improves immunotherapy and is associated with decreased numbers of myeloid-derived suppressor cells in mesothelioma. Celecoxib influences MDSC function. BMC Cancer 2010, 10, 464. [CrossRef] [PubMed]

215. Take, Y.; Koizumi, S.; Nagahisa, A. Prostaglandin E Receptor 4 Antagonist in Cancer Immunotherapy: Mechanisms of Action. Front. Immunol. 2020, 11, 324. [CrossRef]

216. Rotella, D.P. Phosphodiesterase 5 inhibitors: Current status and potential applications. Nat. Rev. Drug Discov. 2002, 1, 674-682. [CrossRef]

217. Hassel, J.C.; Jiang, H.; Bender, C.; Winkler, J.; Sevko, A.; Shevchenko, I.; Halama, N.; Dimitrakopoulou-Strauss, A.; Haefeli, W.E.; Jäger, D.; et al. Tadalafil has biologic activity in human melanoma. Results of a pilot trial with Tadalafil in patients with metastatic Melanoma (TaMe). Oncoimmunology 2017, 6, e1326440. [CrossRef]

218. Weed, D.T.; Vella, J.L.; Reis, I.M.; De La Fuente, A.C.; Gomez, C.; Sargi, Z.; Nazarian, R.; Califano, J.; Borrello, I.; Serafini, P. Tadalafil reduces myeloid-derived suppressor cells and regulatory $t$ cells and promotes tumor immunity in patients with head and neck squamous cell carcinoma. Clin. Cancer Res. 2015, 21, 39-48. [CrossRef]

219. Hashimoto, A.; Fukumoto, T.; Zhang, R.; Gabrilovich, D. Selective targeting of different populations of myeloid-derived suppressor cells by histone deacetylase inhibitors. Cancer Immunol. Immunother. 2020, 69, 1929-1936. [CrossRef] [PubMed]

220. Lu, Z.; Zou, J.; Li, S.; Topper, M.J.; Tao, Y.; Zhang, H.; Jiao, X.; Xie, W.; Kong, X.; Vaz, M.; et al. Epigenetic therapy inhibits metastases by disrupting premetastatic niches. Nature 2020, 579, 284-290. [CrossRef] [PubMed]

221. Hellmann, M.D.; Janne, P.A.; Opyrchal, M.; Hafez, N.; Raez, L.E.; Gabrilovich, D.I.; Wang, F.; Trepel, J.B.; Lee, M.J.; Yuno, A.; et al. Entinostat plus Pembrolizumab in Patients with Metastatic NSCLC Previously Treated with Anti-PD-(L)1 Therapy. Clin. Cancer Res. 2021, 27, 1019-1028. [CrossRef] [PubMed]

222. Li, J.; Wang, L.; Chen, X.; Li, L.; Li, Y.; Ping, Y.; Huang, L.; Yue, D.; Zhang, Z.; Wang, F.; et al. CD39/CD73 upregulation on myeloid-derived suppressor cells via TGF- $\beta$-mTOR-HIF-1 signaling in patients with non-small cell lung cancer. Oncoimmunology 2017, 6, e1320011. [CrossRef]

223. Theate, I.; Van Baren, N.; Pilotte, L.; Moulin, P.; Larrieu, P.; Renauld, J.C.; Herve, C.; Gutierrez-Roelens, I.; Marbaix, E.; Sempoux, C.; et al. Extensive profiling of the expression of the indoleamine 2,3-dioxygenase 1 protein in normal and tumoral human tissues. Cancer Immunol. Res. 2015, 3, 161-172. [CrossRef]

224. Meireson, A.; Devos, M.; Brochez, L. IDO Expression in Cancer: Different Compartment, Different Functionality? Front. Immunol. 2020, 11, 531491. [CrossRef] [PubMed]

225. Long, G.V.; Dummer, R.; Hamid, O.; Gajewski, T.F.; Caglevic, C.; Dalle, S.; Arance, A.; Carlino, M.S.; Grob, J.J.; Kim, T.M.; et al. Epacadostat plus pembrolizumab versus placebo plus pembrolizumab in patients with unresectable or metastatic melanoma (ECHO-301/KEYNOTE-252): A phase 3, randomised, double-blind study. Lancet Oncol. 2019, 20, 1083-1097. [CrossRef]

226. Pico de Coaña, Y.; Poschke, I.; Gentilcore, G.; Mao, Y.; Nyström, M.; Hansson, J.; Masucci, G.V.; Kiessling, R. Ipilimumab treatment results in an early decrease in the frequency of circulating granulocytic myeloid-derived suppressor cells as well as their Arginase1 production. Cancer Immunol. Res. 2013, 1, 158-162. [CrossRef]

227. Li, L.; Wang, L.; Li, J.; Fan, Z.; Yang, L.; Zhang, Z.; Zhang, C.; Yue, D.; Qin, G.; Zhang, T.; et al. Metformin-induced reduction of CD39 and CD73 blocks myeloid-derived suppressor cell activity in patients with ovarian cancer. Cancer Res. 2018, 78, 1779-1791. [CrossRef]

228. Lathers, D.M.R.; Clark, J.I.; Achille, N.J.; Young, M.R.I. Phase 1B study to improve immune responses in head and neck cancer patients using escalating doses of 25-hydroxyvitamm D3. Cancer Immunol. Immunother. 2004, 53, 422-430. [CrossRef] [PubMed] 